Article

\title{
Satellite Survey of Inner Seas: Oil Pollution in the Black and Caspian Seas
}

\author{
Marina Mityagina and Olga Lavrova * \\ Space Research Institute of Russian Academy of Sciences, Moscow 117997, Russia; mityag@iki.rssi.ru \\ * Correspondence: olavrova@iki.rssi.ru; Tel.: +7-495-333-4256 \\ Academic Editors: Elijah Ramsey III, Ira Leifer, Bill Lehr, Xiaofeng Li and Prasad S. Thenkabail \\ Received: 5 June 2016; Accepted: 17 October 2016; Published: 23 October 2016
}

\begin{abstract}
The paper discusses our studies of oil pollution in the Black and Caspian Seas. The research was based on a multi-sensor approach on satellite survey data. A combined analysis of oil film signatures in satellite synthetic aperture radar (SAR) and optical imagery was performed. Maps of oil spills detected in satellite imagery of the whole aquatic area of the Black Sea and the Middle and the Southern Caspian Sea are created. Areas of the heaviest pollution are outlined. It is shown that the main types of sea surface oil pollution are ship discharges and natural marine hydrocarbon seepages. For each type of pollution and each sea, regions of regular pollution occurrence were determined, polluted areas were estimated, and specific manifestation features were revealed. Long-term observations demonstrate that in recent years, illegal wastewater discharges into the Black Sea have become very common, which raises serious environmental issues. Manifestations of seabed hydrocarbon seepages were also detected in the Black Sea, primarily in its eastern part. The patterns of surface oil pollution of the Caspian Sea differ considerably from those observed in the Black Sea. They are largely determined by presence of big seabed oil and gas deposits. The dependence of surface oil SAR signatures on wind/wave conditions is discussed. The impact of dynamic and circulation processes on oil films drift and spread is investigated. A large amount of the data available allowed us to make some generalizations and obtain statistically significant results on spatial and temporal variability of various surface film manifestations. The examples and numerical data we provide on ship spills and seabed seepages reflect the influence of the pollution on the sea environment.
\end{abstract}

Keywords: Caspian Sea; Black Sea; satellite monitoring; sea surface; SAR imagery; oil pollution; surface films; natural hydrocarbon seepages

\section{Introduction}

Nowadays, environmental research technologies based on satellite remote sensing of the Earth are rapidly developing throughout the world in application to different classes of natural objects, including marine environment. Over the past decade, a large number of studies on the development of satellite methods for sea surface oil pollution control have appeared [1-9].

It has been shown that the informational potential of satellite data with high degree of spatial-temporal differentiation can enable a comprehensive study of marine system characteristics, essential for the ecological assessment of water areas. Satellite monitoring is an effective way of monitoring sea surface outside of ports and oil terminals. It allows for continuous monitoring of oil pollution over a vast area of offshore waters including territorial waters of neighboring countries. The latter is particularly important for monitoring trans-border transport of the pollution by sea currents [10]. The availability of satellite information (especially at low or no cost) has significantly broadened its application in scientific and applied research and has largely contributed to the development of remote sensing systems. 
In the sea, oil pollution may result from releases of crude oil and oil products from tankers, offshore platforms, drilling rigs, wells, pipelines as well as from releases of bunker fuel, waste oil, and bilge water from other types of ships (cargo, ferry, tourist, military, fishery, etc.). This may occur accidentally or during routine operations at sea or in ports. Oil comes to the sea also with river runoff and from the ocean bottom due to natural seepages.

Scientific problems related to satellite monitoring of sea surface oil pollution are being addressed by researchers worldwide. The main foci are: (a) scattering of SAR signal of various polarizations by films of different origins; and (b) corresponding rearrangement of the surface wave spectrum [11-15]; (c) distinction of oil pollution in the period of ice cover formation [16]; (d) automatic detection of oil spills in radar images [17,18]; and (e) development of a system of operational multisensor pollution monitoring of vast marine areas $[4,8,19,20]$.

Methods and technologies of remote sensing have been applied in practice [4,21-24]. The European, Canadian and Italian Space Agencies conduct routine monitoring of oil pollution of the sea surface. With satellites of their own equipped with SARs, they have a priority in operational shooting of any point in the ocean and land and an extensive network of scientific and commercial dealers supplying raw and processed SAR data.

A good example of the sea surface pollution monitoring organized by EU member states is the CleanSeaNet project of the European Maritime Safety Agency (EMSA). Covering all European sea areas, CleanSeaNet analyzes SAR images to detect possible oil spills on the sea surface. When a suspected oil spill is detected in national waters, an alert message is delivered to the relevant country. However, it is important to note that CleanSeaNet does not detect real oil spills but only indicates "possible oil spills" [25]. This is because CleanSeaNet uses solely automatic oil spill detection algorithms that are based exclusively on SAR data, which results in high probability of false alarm. The discrimination between oil spills and look-alikes requires more information and most often on-site verification [25]. According to EMSA estimations, the level of false alarm in the coastal zone reaches $50 \%$. EMSA publishes summary maps of ship discharges revealed by the CleanSeaNet service, but neither the eastern part of the Black Sea, nor the Caspian Sea are covered. The European countries have been quite successful in preventing major sea surface oil pollution and establishing a system for monitoring sea surface using aerial and satellite surveillance [4]. Unfortunately, many countries cannot still afford any adequate monitoring program. For example, none of the Caspian countries, except Russia, carry out satellite monitoring of the Caspian Sea.

Previously, satellite survey was carried out mostly in the northern Caspian, where Russian offshore oil drilling platforms are located. As shown in [26], despite extensive oil exploration and production (by LUKOIL (Moscow, Russia), and others) in the northern Caspian, no oil spills related to oil production have been detected. In addition, oil pollution due to illegal ship discharges was addressed. Results of routine satellite oil spill monitoring in the Northern and Middle Caspian Sea (2009-2013) showed that most of the detected oil spills in these regions were from small ship-made discharges $(\leq 10 \mathrm{sq} . \mathrm{km})$ related to cargo traffic and fisheries. Other types of oil pollution escaped detailed study. In $[12,27,28]$, the presence of a large number of oil slicks in SAR data taken over the Middle Caspian is just noted, while natural oil seeping is mentioned only as an ill-estimated source of pollution in the southern part of the Caspian Sea. Notice that the above studies of oil pollution in the Caspian Sea are only based on SAR data, but, as we demonstrate below, they are not sufficient for a comprehensive description of the state of pollution.

Studies of oil pollution in the Black Sea primarily focus on its northeastern part. A good example is the operational monitoring of the status and pollution of the Russian sectors of the Black and Azov Seas that has been conducted annually since 2003, from April to October, under the direction of the Scientific Research Center "Planeta" [20,29]. The main attention is paid to detecting and mapping of ship spillages. A comparison of oil pollution in the Black and Caspian Seas in [26] is also performed for ship spills. Meanwhile, there are multiple instances of natural hydrocarbon showings both in the Black and Caspian Seas. Hence it is of interest to retrieve, using satellite data, the most complete picture 
possible of sea surface oil pollution including natural hydrocarbon showings in the Black and Caspian Seas. Here, the term "natural hydrocarbon showings" embraces mud volcano activities, natural gas and oil emersions and gas hydrates. It is important to reveal features typical of each pollution type, calculate their parameters and estimate contribution into total pollution.

The essential point in the reported studies of oil pollution in the two seas is that they all are based on radar images obtained by SARs. Among the many different sensors SAR is definitely the most suited instrument for oil spill monitoring because of its high ground resolution and independence of cloud and light conditions. Oil appears as a dark patch in SAR images because of its damping effect on backscattered radar signal [30-32]. Nevertheless, unambiguous oil detection based only on SAR data is still problematic. A number of reasons complicate the interpretation of SAR images and discrimination of oil pollution: under certain hydrometeorological conditions, especially under low wind, oil spills can be easily confused with other phenomena, the so-called "radar look-alikes". Among look-alikes are organic films, some types of ice, land shadow zones, rain cells, upwelling zones, internal waves in the atmosphere and ocean, etc. [33-35]. A lack of understanding may lead to slicks going undetected, or to an unacceptable numbers of 'false positives'. We believe that reliable detection of oil on the sea surface is best achieved by using SAR as part of a multisensor approach, which uses all available information from satellite data and ancillary data sources, integrating this with background information about an area and hydrodynamic models used to forecast oil spill evolution and drift. We first applied this approach during a pilot project on complex monitoring of the southeastern Baltic Sea, initiated by LUKOIL-Kaliningradmorneft and conducted in June 2004-November 2005, and since then have continuously improved it with the aim to achieve satellite control of sea surface oil pollution [36].

The goals of our work reported in this paper were twofold. First, we wanted to improve the techniques and raise reliability of surface oil detection and discrimination between oil types. Second, we attempted to fill the gap in the knowledge of oil pollution patterns in the whole area of the Black Sea, as well as the Middle and Southern Caspian Sea, using the improved techniques and based on a large bank of satellite and in situ data collected during our monitoring experience of more than ten years $[8,9,20,29,37-39]$.

These goals are broken down into primary objectives: (1) improving methodologies for the synergistic use of satellite data at microwave, thermal infrared and visible wavelengths to monitor sea surface oil pollution; (2) retrieving the dependence of radar signatures of oil patches on sea surface wind/wave conditions and establishing the limits of validity of oil pollution parameters derived solely from SAR imagery; (3) retrieving the influence of hydrodynamic parameters (current, wind and wave fields) on transport. spreading and evolution of oil pollution in SAR and optical data; (4) mapping oil pollution due to ship spills on the whole aquatic area of the Black Sea as well as oil pollution of the sea surface caused by natural hydrocarbons showings from the sea bottom in the south-eastern of the Black Sea; (5) mapping oil pollution in the Middle and Southwestern Caspian Sea; (6) identification of the most heavily polluted regions of the Black and Caspian Seas.

\section{Study Areas}

\subsection{The Black Sea}

The Black Sea is one of the most isolated seas from the world oceans, an almost closed sea, bordered by six countries with well-developed industry and intense agriculture in coastal areas. There are dozens of industrial ports, some of which with oil terminals. As shown in Figure 1a the sea carries intense marine traffic [40]. The shipping activities, including oil transport and oil handled at terminals, have a number of negative impacts on the marine environment and coastal zone.

Based on our experience of satellite monitoring of various seas $[9,23,36]$, we may state that, for the Black Sea, the problem of discriminating between various types of sea surface films is very acute. Alongside with oil pollution from ship spills, there are films originating from intense phytoplankton bloom, or active underwater mud volcanoes, or natural hydrocarbon outflows (methane seepages), 
that can be found practically everywhere [41]. In addition, SAR signatures of surface slicks produced by the three sources of films are often very similar.

In particular, a relatively small area (about $20 \mathrm{sq} . \mathrm{km}$ ) of the south-eastern part of continental slope with four cold methane seepages (Figure 1b) became something like a natural laboratory. Acoustic research, accompanied by detailed geochemical analyses, ground sampling, and examination of gas hydrates and escaping gases, were conducted there during field experiments. These field works were carried in this area in 2005 as part of a UNESCO training and research program as well as in 2007 and in 2011 within the German Methane and Methane Hydrates (METRO) project. Investigations on the south-eastern continental slope [41,42] have shown that there are gas jet seepages where methane coexists simultaneously in free form and as gas hydrates, which is very unique for the Black Sea. The characteristic feature of these seepages is the presence of oil traces in the seabed gas hydrates. Accordingly, oil slicks were observed on the sea surface in the regions where the seepages were revealed. The most probable cause of these seepages is the unique geological structure of the southeastern margin of the Black Sea [43].

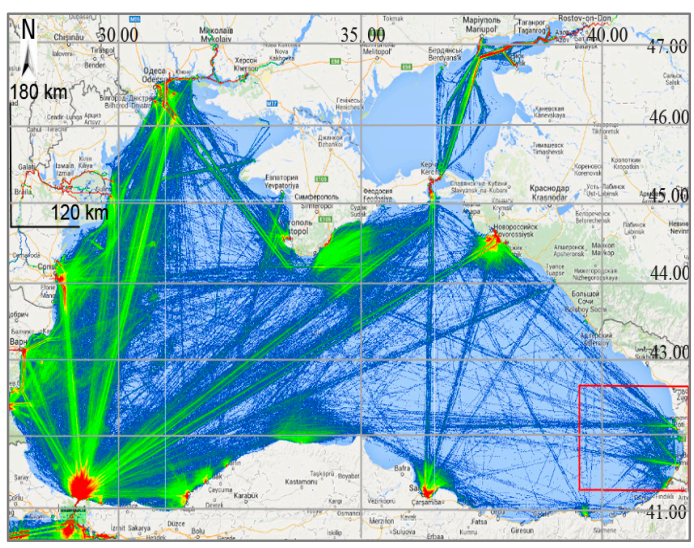

(a)

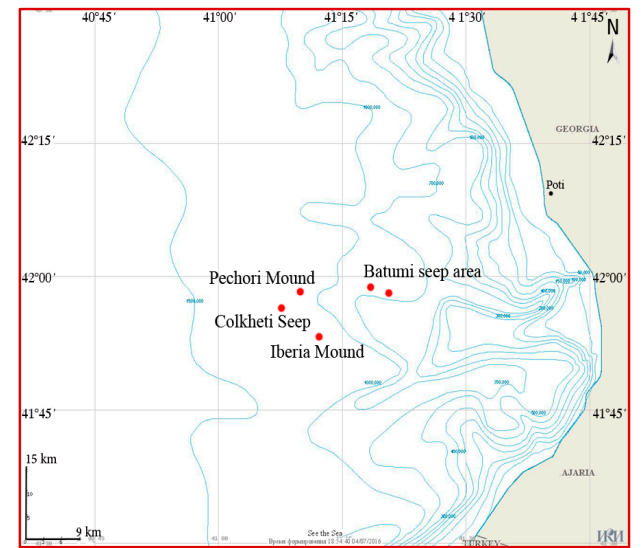

(b)

Figure 1. (a) Black Sea shipping traffic density map. The color coding represents traffic density in each area. The numbers refer to distinct vessels on a daily basis and count positions per square $\mathrm{km}$. Blue-less than 30; Green-30 to 70; Yellow-71 to 140; Red-more than 140. Red rectangle indicates the area of natural hydrocarbon seepages on the southeastern shelf slope; (b) Locations and bathymetry of the natural hydrocarbon seepages on the southeastern shelf slope.

\subsection{The Caspian Sea}

Unique and rich in natural resources, the Caspian Sea has no natural connection with the world oceans and is the largest inland body of water in the world. It contains about 3.5 times more water, by volume, than all five of North America's Great Lakes combined. The Caspian is a lake by its geographical definition although it is not a freshwater lake. The Caspian has characteristics common to both seas and lakes, but its size, hydrometeorological conditions, currents, water level oscillations, flora and fauna are more characteristic of seas.

The Caspian Sea belongs to the world largest oil-bearing regions. Total oil reserves of the Caspian Sea region are estimated at above 250 billion barrels [44], which puts it in the second place after the Middle East. The development of shelf and offshore oilfields began back in the late 19th century. The main sources of the Caspian Sea surface pollution are considered to be offshore oil production as well as natural oil seepages at the sea bottom. According to some estimates [45], about one million tons of oil leaks annually into the Caspian Sea.

Many of our results presented in this paper are based on satellite data obtained over the major oil-producing region "Neftyanye Kamni" (translated as "Oil Rocks" in English, and hereafter we will use this name for convenience) in the Middle Caspian. The location of the Oil Rocks area is indicated 
by red rectangle on the map in Figure 2a. An enlarged fragment of the satellite VIS data showing Oil Rocks oil-producing area is depicted in Figure $2 b$. The output of this oilfield, discovered and brought into production in the late 1940s, is 10 million tons of crude oil annually. Oil films are always present on the sea surface in that region covering areas of 200-1000 sq. km [46]. However, the sea surface pollution in the vicinity of Oil Rocks is caused not only by "dirty" oil production techniques (oil production and oil-well drilling, underwater oil-rig repair, pipeline breaks). Even before drilling started at Oil Rocks in 1949, the sea surface in this region was famous for its natural oil slicks. It is now believed that the oil pollution around this oil-drilling platform is caused not solely by man-made discharges and leaks, but is rather a result of natural seeping activity at the sea bottom. The amount of oil ingress to the sea in this region can vary between 100 and 500 tons per day. Oil patch size, its spreading and evolution depend on meteorological conditions. The region of Oil Rocks can be used as a natural laboratory for studying the effect of wind/wave conditions on oil patches as well as on formation of oil slick signatures in SAR images. The system of surface currents in the area around Oil Rocks is rather complicated and unstable. The highest current velocities in the Caspian Sea are observed in this area [47].

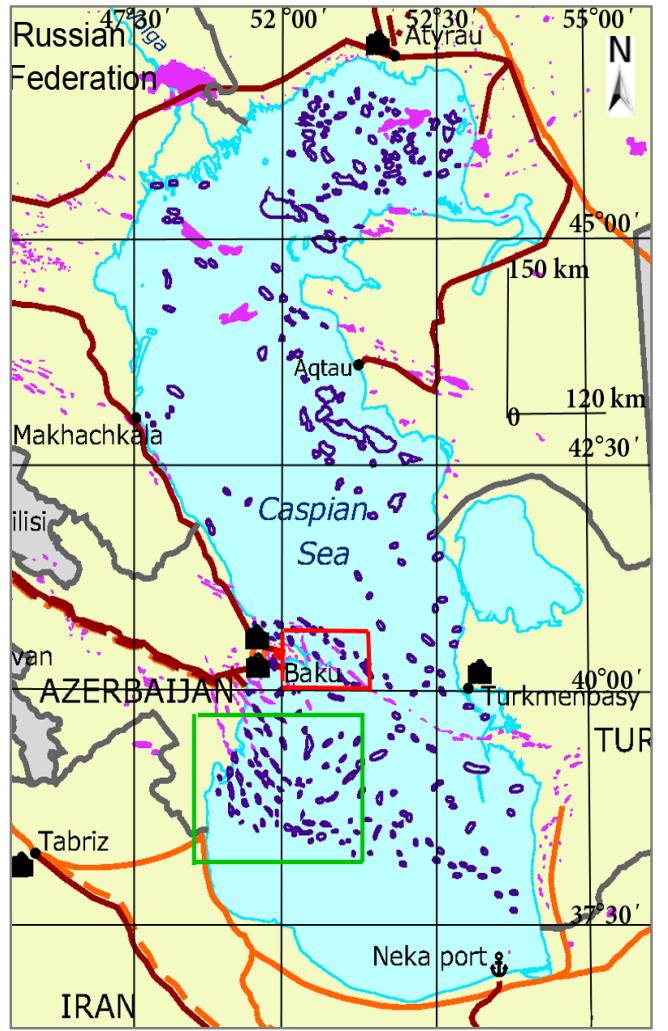

(a)

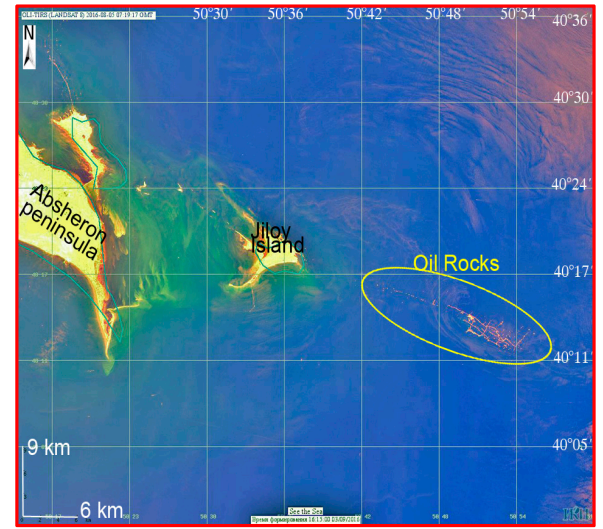

(b)

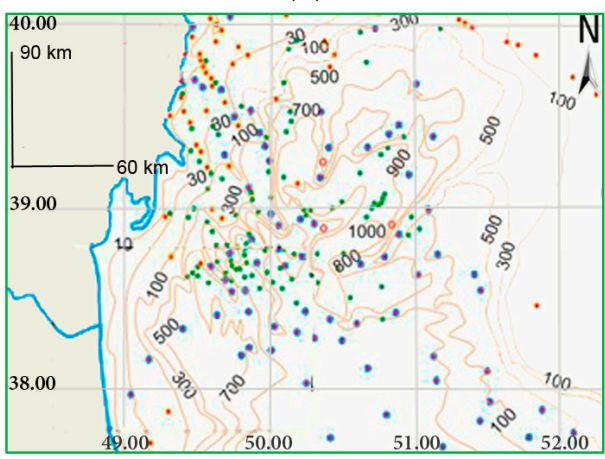

(c)

Figure 2. (a) The map of the Caspian Sea. Magenta indicates oil and gas fields. Deep purple indicates prospective fields [48]; Red rectangle indicates the location of the Oil Rocks oil-producing area; Green rectangle indicates the area of the natural mud volcanoes on the southeastern shelf slope; (b) Part of an Landsat-8 OLI image taken on 7 May 2016 at 19:17 UTC over Oil Rocks oil-producing area; (c) A map of mud volcanoes and bathymetry of the area.

Mud volcanoes and seepages at the Caspian Sea bottom have been known about for a long time. The largest number of mud volcanoes (more than 300) and the biggest ones are concentrated at the north-western edge of the South-Caspian Depression (Figure 2c) [49]. The majority of South-Caspian Depression mud volcanoes are in the seepage stage of their lifecycle and discharge mud, water, gas and oil. Intensification of activity of the underwater volcanoes and seepages results in contamination 
of the sea surface by oil and mud patches. Sometimes, mud volcanoes manifestations may serve as an indicator of oil and gas reserves, so these phenomena attract much attention of researchers. Some examples of their manifestations in radar images are discussed in [50,51].

\section{Data and Methods}

\subsection{The Data and Data Processing}

Our monitoring of surface pollution and sea dynamics was based on a combined analysis of satellite imagery obtained by various sensors that operate in different bands of the electromagnetic spectrum. The main data source was high-resolution Advanced Synthetic Aperture Radar (ASAR) Envisat (till the spring of 2012) and Sentinel-1 (starting from October 2014) SAR imagery.

The basic SAR data were complemented by other satellite information on sea surface and water condition, such as sea surface temperature, suspended matter and chlorophyll-a concentration, mesoscale water dynamics, etc. These were provided by data in visible (VIS) and Infrared (IR) bands by Envisat MERIS (MEdium-spectral Resolution Imaging Spectrometer), Terra/Aqua MODIS (Moderate Resolution Imaging Spectroradiometer) and scanning radiometers Thematic Mapper (TM), Enhanced Thematic Mapper Plus (ETM+), Operational Land Imager (OLI) of Landsat-5,7,8. The complementing satellite data were selected quasi simultaneous to the SAR images in order to facilitate the differentiation between various types of surface films, reveal meteorological and hydrodynamic processes, and determine factors governing the spreading and evolution of pollutants. In addition, meteorological data were provided by local coastal stations.

About 4500 high resolution SAR images of the Black and Caspian Seas acquired in the period from February 2009 to April 2012 by Envisat ASAR and ERS-2 SAR were processed and analyzed. Most of the images were complemented with VIS and IR data for the times close to SAR data acquisitions. The attempt was to combine as much quasi-simultaneous data from different sensors as possible. The SAR images were obtained via internet from the three European receiving stations ESRIN, MATERA and KIRUNA in near-real time mode in the framework of scientific projects of the European Space Agency [8]. Since October 2014, we have used Sentinel-1A data freely available at [52]. At present, the number of collected Sentinel-1A images of the seas is over 6000 . The vast amount of accumulated experimental data has allowed us to ensure statistical reliability of our results.

Data were processed and analyzed by means of a satellite information system created at the Space Research Institute of the Russian Academy of Science (IKI RAS). The system is named "See the Sea" (STS). The functionality, the goals and the current state of the STS in details are described in [53]. The most essential and critical for our study elements of the system and data processing use are given hereafter.

In STS, a special emphasis is placed on joint analysis of data obtained in different ranges-VIS, IR, microwave-at different spatial resolutions by various satellite sensors. It has a specialized cartographic web-interface allowing users to search distributed image archives using sensor type, time interval and location as search criteria. An image selected from the catalog is visualized in the map area of the interface along with the geographic basis and related cartographic data. All information (regardless sensor type or product) is displayed in the same cartographic projection for a given geographic area. The service includes instruments for complex analysis of various processes and phenomena in the world oceans, qualitative and quantitative estimates of their properties, spatial and temporal variations, revealing conditions of their generation and evolution [54].

The process of analysis of the dataflow from radar observations is difficult to automate. STS provides the user with a set of tools for visual detection of processes and phenomena, their description using various supplementary information and storage of the results in a specialized database for further use.

The description of an oil slick on the sea surface includes: geographic coordinates of the slick start, end (in case of a slick band) and centre points, slick band length, total polluted area, the presence 
of a ship nearby as a possible source of oil pollution and its coordinates at the moment of imaging. All information stored in the specialized database is used not only for oil pollution mapping but also for obtaining various estimates such as number of illegal discharges from ships, spill length, polluted area, spilt oil amount (in a particular region, over the whole sea, for a given period of time, etc.).

\subsection{Methodology of Oil Spill Detection in SAR Images}

The principal indicative characteristics of an oil spill are: (i) linear dimensions of a few kilometers for routine (non-accidental) spills; (ii) sharp boundaries; (ii) presence of nearby ships.

Larger low-contrast regions without sharp boundaries are associated with wave damping due to other reasons: low wind or oceanic processes (currents, upwelling, etc.). As a rule, it is impossible to detect oil spills inside these regions in the radar imagery. In addition, oil spill detectability falls dramatically for wind speeds over $10-12 \mathrm{~m} / \mathrm{s}$.

One of the most important features helping to distinguish a ship-made oil spill in radar images is its geometric shape. When oily water is discharged by a moving ship under moderate wind and calm sea surface, a narrow slick band along the ship route appears in a radar image taken after the spill. If the discharge occurs not long before the moment of image acquisition, the slick band is narrower because the track is still fresh and not diffused. Usually in such situations, it is possible to identify the ship responsible for the spill. Some ships continue dumping wastewaters for dozens of kilometers along their way. Figure $3 a, b$ present examples of radar signatures of fresh spills from moving ships. Figure 3a shows a part of a radar image taken in the Kerch Strait area under low wind and low surface waves conditions. A radar image shown in Figure $3 \mathrm{~b}$ was obtained in the central part of the Black Sea under moderate wind conditions and more intense surface waves. In both cases, the narrowings of the slicks in the north-east and south-east directions, respectively, indicate directions of the ships' courses. Bright points at the north-eastern and the south-eastern ends of the slicks indicate locations of the ships at the moment the image was taken.

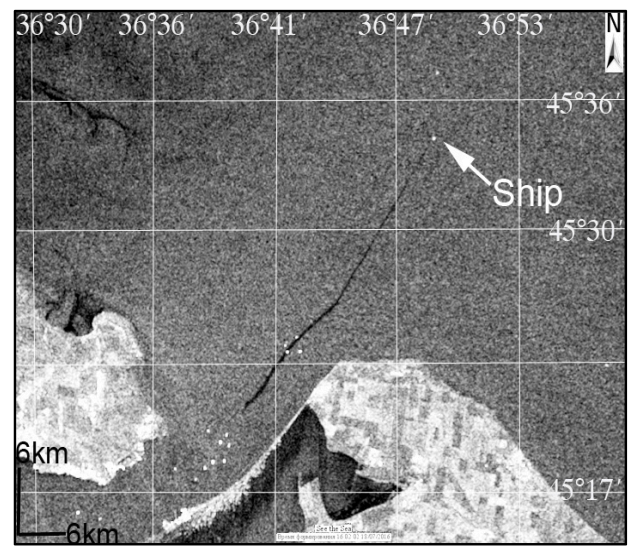

(a)

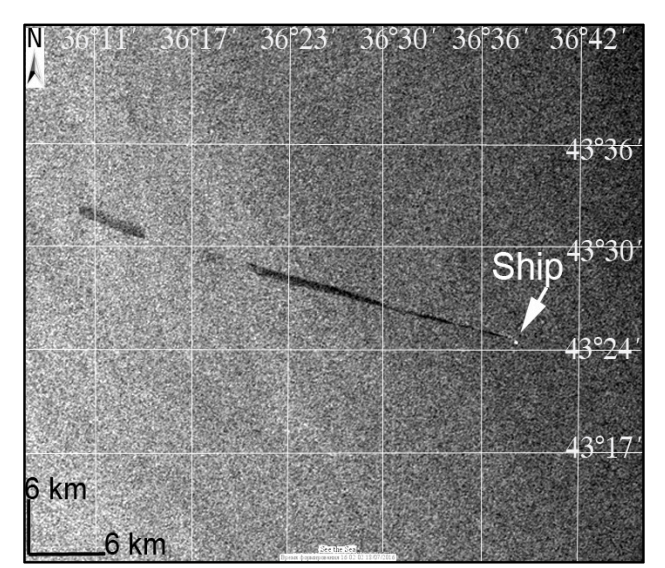

(b)

Figure 3. Fresh spills from moving vessels seen in SAR imagery of the Black Sea: (a) ASAR Envisat, 10 June 2008, 19:18 UTC. Length 21 km; (b) ASAR Envisat, 10 June 2008, 19:18 UTC. Length 45 km.

Special attention needs to be paid to multiple spills from moving vessels. They are most likely caused by oil tankers washing their tanks in the open sea. In our earlier work [38] we demonstrate that, sometimes, it is even possible to deduce the number of tanks of a tanker from a SAR image. We often detect such events in different parts of the Black Sea, most frequently occurring at night-time. Such examples are given in Figure 4a,b. Figure 4a shows a well-defined dashed spill of nearly $115 \mathrm{~km}$ in length. The spill chain ends by a bright point indicating the position of a ship moving in the north-east direction. The spill occurred shortly before the radar image acquisition and the film had just started to spread. The spill gets narrower closer to the ship and one can observe high radar contrast between 
the spill area and the sea surface. The example shown in Figure $4 \mathrm{~b}$ is characterized by wider film spreading and lower contrast of the dashed spill extended for $21.5 \mathrm{~km}$. The latter discharge took place a few hours before the image recording and the responsible ship could not be found.

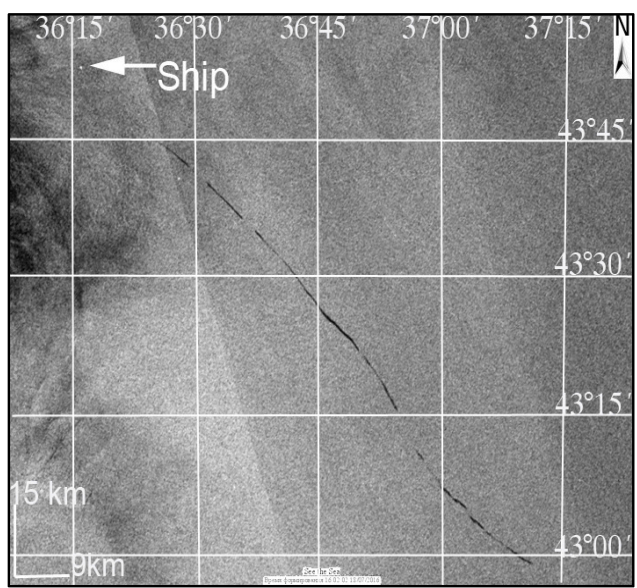

(a)

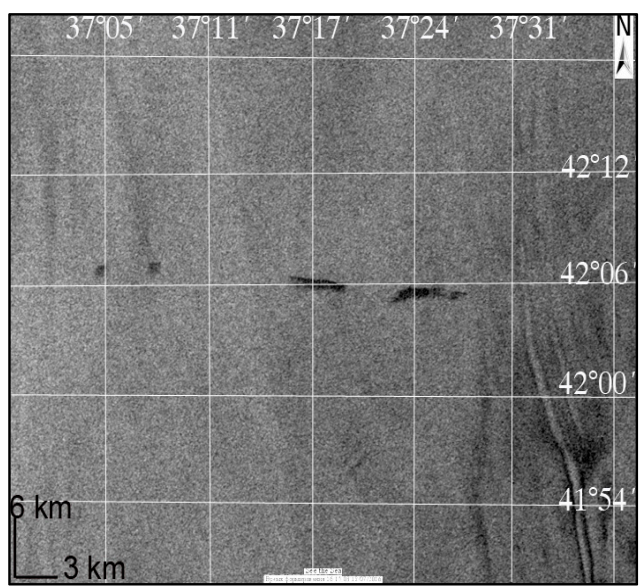

(b)

Figure 4. Multiple spills from moving vessels seen in satellite SAR imagery of the Black Sea: (a) ASAR Envisat, 23 June 2011, 19:29 UTC. Oil spills chain. Total length 115 km; (b) ASAR Envisat, 13 February 2009, 19:23 UTC. Oil spills chain. Total length $21.5 \mathrm{~km}$, total area-8.2 sq. km.

Wind can directly force the film to drift over the sea surface, oil being accumulated on the leeward of the patch. In addition, near-surface wind can induce dynamic processes in the upper layer of the sea. Langmuir circulation is the most common process which is caused by wind-driven spiral circulations of alternating directions with axes almost parallel to the wind direction. Inside a vortex, water moves on a plane perpendicular to the wind velocity vector. Thus, alternating divergence and convergence zones appear on the sea surface, with the oil being concentrated in the latter zone. An oil spill transforms into streaks that are referred to as "comb-like structure", the spill area increases. The presence of a comb-like structure is only characteristic of oil pollution and thus differentiates it from films of other origins. Figure $5 \mathrm{a}, \mathrm{b}$ show examples of spills transformed into comb-like structures.

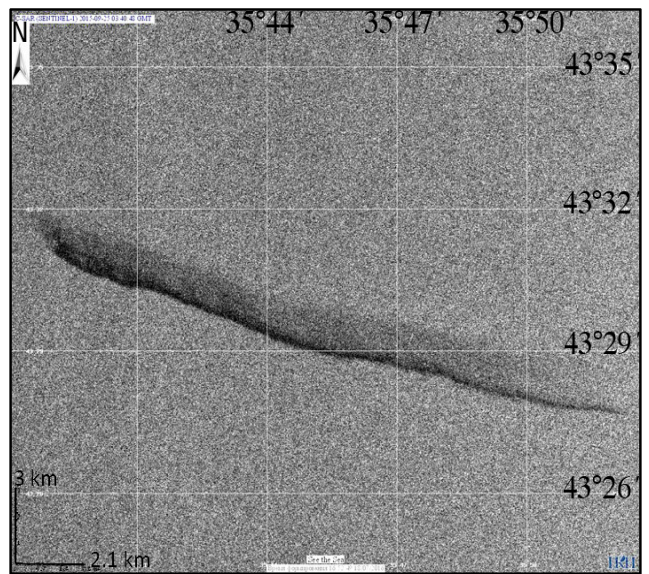

(a)

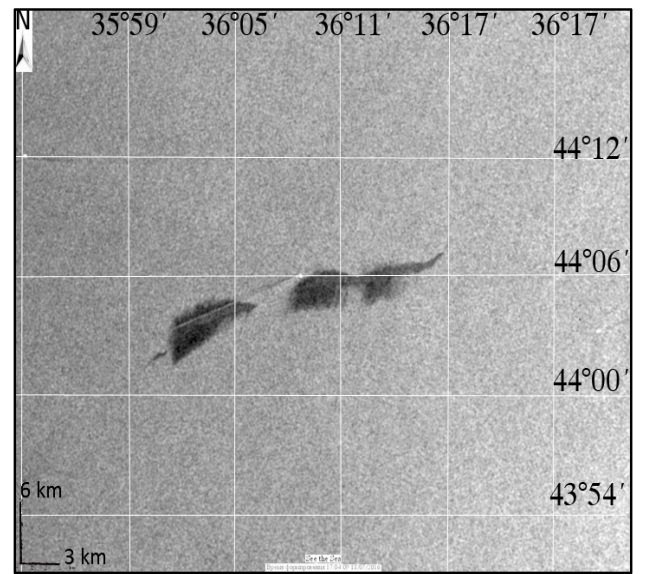

(b)

Figure 5. Weathered oil spill of comb-like structure seen in satellite SAR imagery of the Black Sea: (a) SAR Sentinel-1, 25 September 2015. Area-17 sq. km; (b) ASAR Envisat, 12 June 2010. Weathered oil spill of comb-like structure. Area-28 sq. km. 
3.3. Dependence of Radar Signatures of Oil Patches on Sea Surface Wind/Wave Conditions and Reliability of Polluted Area Size Retrieval from the Radar Data

The near-surface wind was identified as the most important factor affecting the reliable detection of oil pollution on the sea surface via radar imagery. All results presented in this section are based on satellite data obtained over the Oil Rocks oil-producing area in the Middle Caspian. (Figure 2b).

Essentially all SAR images taken at moderate wind speeds (3-8 m/s) over the Oil Rocks area carry signatures of oil slicks. Envisat ASAR imagery taken in 2009-2011 was compared with that obtained by Sentinel-1 SAR in 2014-2015. It was found that the amount of surface oil slicks in SAR images is practically the same for both observation periods. In our previous work [39] we demonstrated that the reduction in the Normalized Radar Cross Section (NRCS) within a slick can reach 2-11 dB depending on film thickness, oil concentration and wind speed as well as on the type of sensor and polarization. Figure 6 presents characteristic examples of oil slicks seen in radar images of Oil Rocks under moderate winds. The inset graphs depict variations of the radar backscatter along the marked transects.

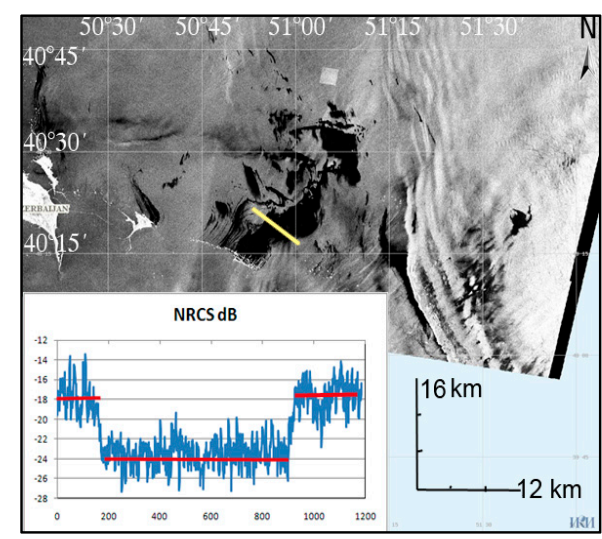

(a)

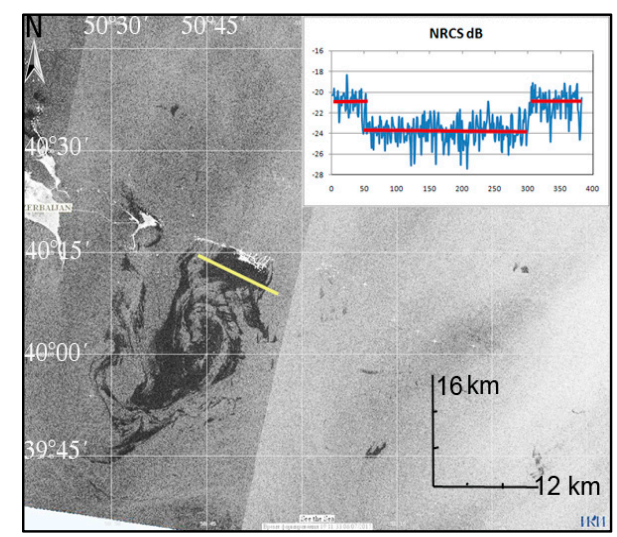

(b)

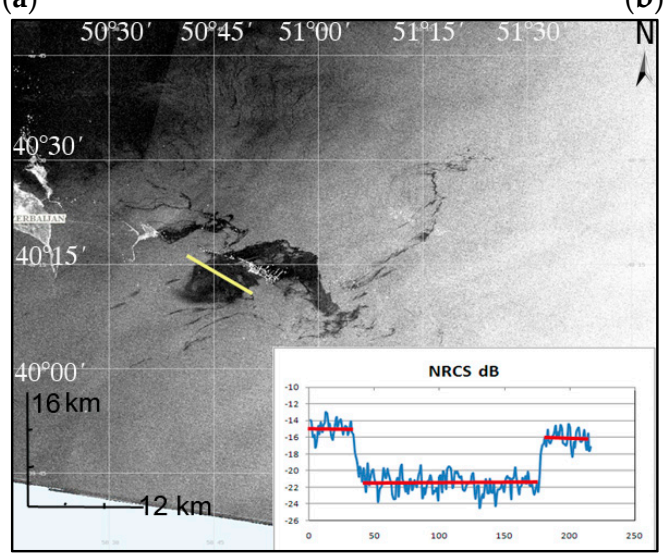

(c)

Figure 6. (a) A part of a VV-polarized Sentinel-1 SAR image of 29 May 2015, 02:43 UTC, showing oil patches near the oil platform. Total area of the oil slick is 375 sq. km; (b) A part of an HH-polarized Envisat ASAR image of 13 July 2010, 06:39 UTC, showing oil patches near the oil-drilling platform. Total area of the oil slick is $515 \mathrm{sq}$. km; (c) A part of an HH-polarized Envisat ASAR image of 7 May 2010, 06:45 UTC, showing oil patches near the oil-drilling platform. Total area of the oil slick is $290 \mathrm{sq} . \mathrm{km}$.

At high wind speeds (exceeding 9-10 m/s), both oil and biogenic polluting films are disrupted by wind and waves, and cannot always be identified in radar images. A radar image taken under unfavorable wind speed of $11 \mathrm{~m} / \mathrm{s}$ in presence of convective processes in the sea-atmosphere boundary layer is depicted in Figure 7a. One can only see a very small dark area of decreased radar backscatter in the immediate vicinity of the oil-drilling platform. Intense atmospheric processes that induce 
considerable variation of the near-surface wind field may also hamper detection of surface films in SAR images. The atmosphere is transparent for the radar signal and atmospheric processes only become visible in radar images via inhomogenities of the gravity-capillary component of the sea-surface wave field. Wind field variations modulate short gravity waves at the sea surface resulting in the inhomogenities of the backscattered radar signal distribution. We found that sometimes atmospheric signatures can cover the major part of a radar image inducing considerable variations of the signal intensity. This often makes it impossible to identify manifestations of oil films on the sea surface. Figure 7b shows a Sentinel-1 SAR image with distinct quasi-periodic modulations of the radar signal. They appear to pertain to surface wind fluctuations connected with atmospheric gravity waves propagating in the marine atmosphere. Note that in this case the radar signatures of oil floating on the sea surface are very weak, about $1.5 \mathrm{~dB}$. We have found that the areas of oil patches detected in SAR images in conditions of strong winds or/and near-surface atmospheric effects are significantly smaller than those detected under moderate winds. Hence, in the presence of intense atmospheric processes, the sizes of polluted areas retrieved solely from SAR data are most likely underestimated.

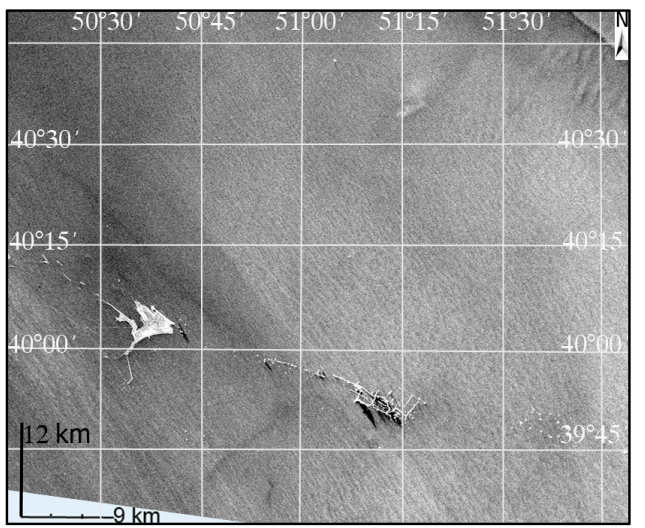

(a)

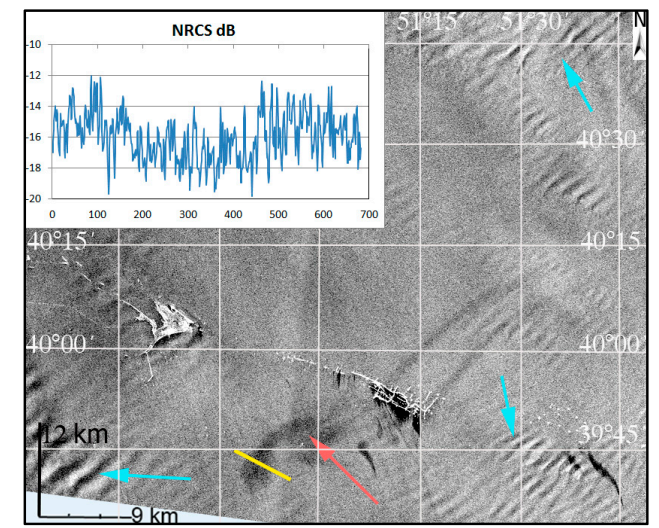

(b)

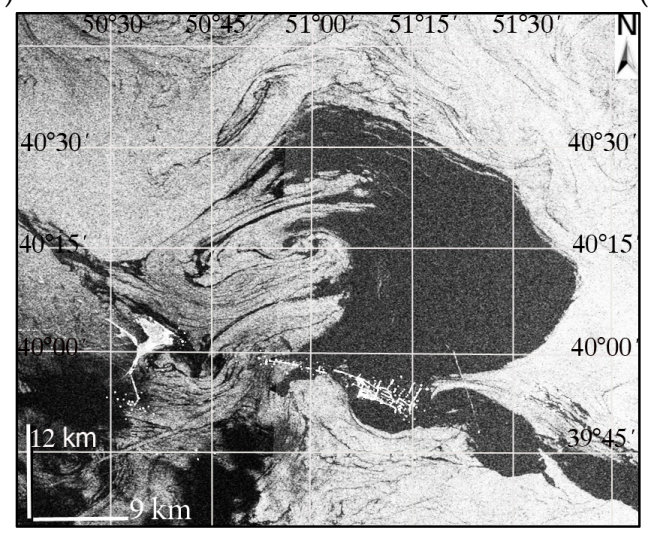

(c)

Figure 7. (a) A part of a VV-polarized Sentinel-1 SAR image of 18 March 2015, 02:43 UTC, showing the sea surface near the oil platform. A small area of about $4 \mathrm{sq}$. $\mathrm{km}$ covered by oil films can be identified near the oil platform; (b) a part of a VV-polarized Sentinel-1 SAR image of 22 June 2015, 02:43 UTC, over the same area. Quasi-periodic oscillations of radar signal (marked by blue arrows) are caused by atmospheric gravity waves propagating in the near-surface layer. Areas of radar signal attenuated due to presence of oil on the surface are marked by the red arrow. The inset graph depicts variations of the radar signal along the yellow transect. Total polluted area is $70 \mathrm{sq} . \mathrm{km}$; (c) a part of an $\mathrm{HH}$-polarized Envisat ASAR image of 4 August 2010, 06:45 UTC, obtained at low wind.

The existence of these low scattering (dark) areas in SAR images increases the "false positive" probability in oil pollution monitoring. In SAR images obtained under low near-surface wind, the 
lack of backscatter can be related not only to the presence of oil-containing films, but also to extremely weak capillary-gravity component of surface waves. Hence the sizes of polluted areas derived from SAR data taken at low winds can be overestimated. Figure 7c depicts an Envisat ASAR image of Oil Rocks taken at low wind. The area of the slick around the oil-extracting platform is approximately 835 sq. km.

\subsection{Joint Analysis of Radar Data and Data of Optical Sensors}

Optical images, especially obtained in sunglint zones, can provide additional information on the processes and phenomena at the sea surface, especially in low wind areas. These are areas where the radar backscatter is low, and the ocean surface may appear featureless and uniformly dark across a SAR image. An oil film in VIS images may be visible even better than in SAR images, since the observed contrasts are caused not only by smoothing of surface waves by oil, but also by the differences in optical characteristics of clean water and the film [55].

To find out whether film pollutions detected on the sea surface belong to oil-containing or biogenic films, we conducted a joint analysis of radar and optical data. Examples of radar and optical expressions of surface oil are shown in Figure 8. In the radar image oil film region manifest themselves as filamentary slicks, similar in structure to biogenic film manifestations (Figure 8a). In the optical data, oil-containing and biogenic films manifest themselves differently, because they change the sea surface reflective properties differently [55]. In the colour-synthesized Landsat-8 OLI image (composition of channels 4,2, and 1), oil-containing slicks are bright and biogenic films do not manifest themselves (Figure 8b).

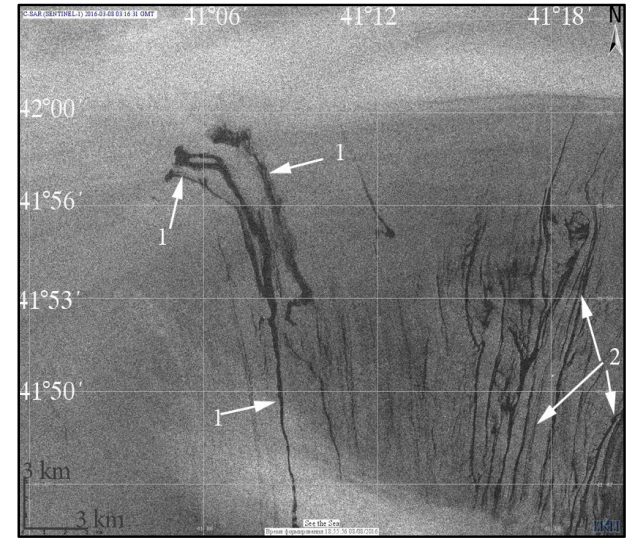

(a)

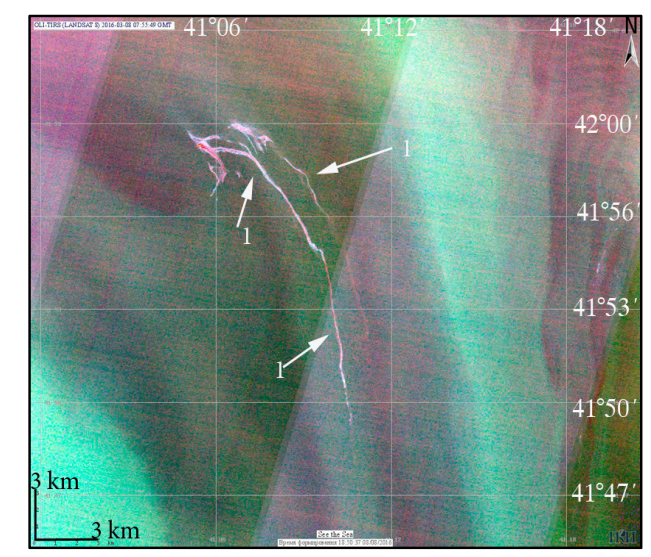

(b)

Figure 8. An example of joint analysis of optical and radar data. (a) A part of a VV-polarized Sentinel-1 image of 8 March 2016, 03:16 UTC; (b) A part of a Landsat-8 OLI image (composite of 4, 2 and 1 spectral channels) of 8 March 2016, 07:55 UTC. 1-surface slicks from methane seepages; 2-biogenic films.

In another example, optical multispectral sensor Landsat-5 TM and Envisat ASAR images collected within 24-h of each other over a marine oil production area in the Middle Caspian Sea depict differences possible in optical and radar image content (Figure 9). A colour composite of Landsat-5 TM data acquired 5 June 2011 at 07:08 UTC at a resolution of $30 \mathrm{~m}$ in sunglint condition near the Oil Rocks oil platform manifests oil pollution by a typical iridescent pattern with a darker halo indicating non-uniformity of the oil film thickness. The area of pollution is estimated at $610 \mathrm{sq} . \mathrm{km}$. In addition, elements of mesoscale water dynamics are revealed due to the presence of a considerable amount of suspended matter in water near the Absheron Peninsula (northwest corner of the image). In an Envisat ASAR image showing the same region on 6 June 2011 at 06:57, the pollution occupies a smaller area of 416 sq. km and no film thickness differences can be inferred. 


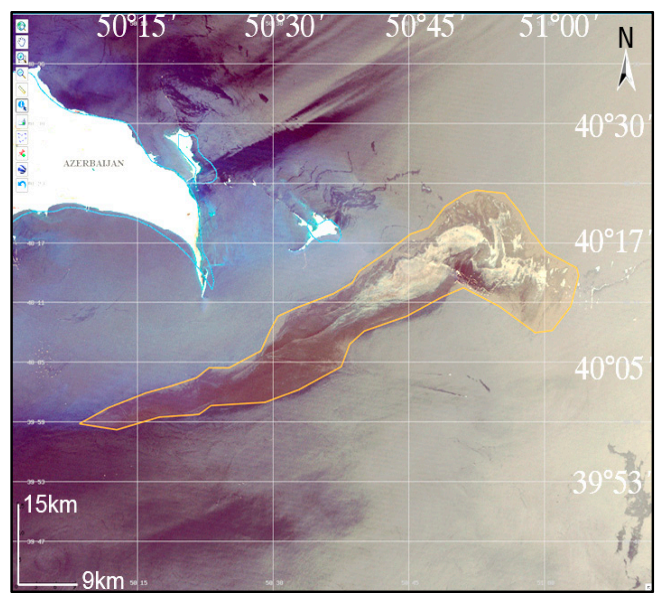

(a)

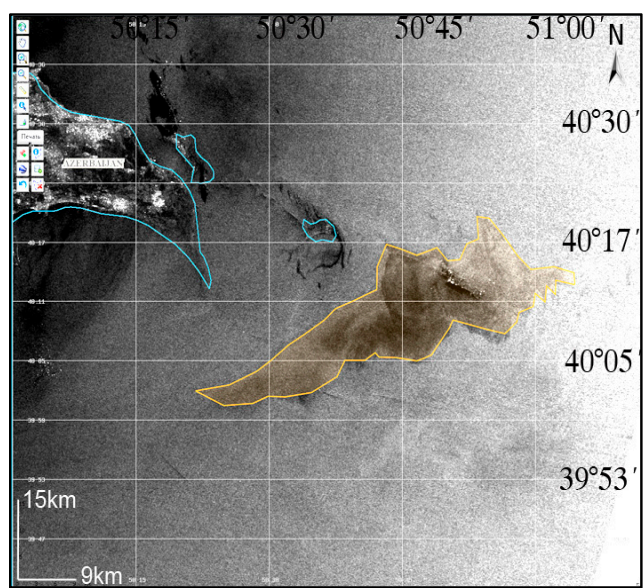

(b)

Figure 9. An example of joint analysis of optical and SAR data. (a) Landsat-5 TM colour composite (R: 630-690 nm; G: 520-600 nm; B: 450-520 nm) of 5 June 2011, 07:08 UTC, resolution $30 \mathrm{~m}$, in sunglint over the Oil Rocks area; (b) Envisat ASAR image of 6 June 2011, 06:57 UTC, of the same location.

An Sentinel-1 SAR image in Figure 10a depicts vast dark areas of decreased radar backscatter caused by low near-surface wind. It is impossible to accurately identify oil patches in this image. Meanwhile, adding optical data taken by Landsat- 8 OLI sensor in sunglint to the analysis helps solve this problem, i.e., reveal oil patches and exclude areas of low wind.

Figure $10 \mathrm{~b}$ depicts a fusion of the Landsat-8 OLI false-colour and Sentinel-1 SAR images. The areas covered by oil (outlined by the magenta ellipse) are seen in the optical image as characteristic iridescent patches with a darker halo, in accordance with the film thickness non-uniformity.

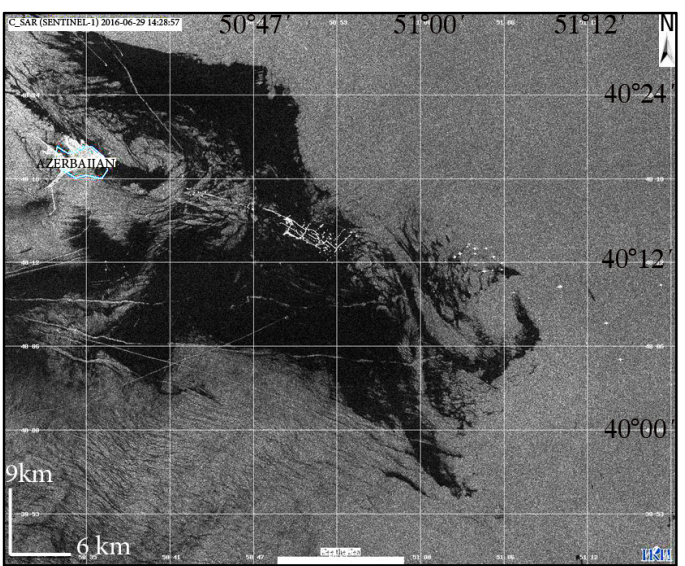

(a)

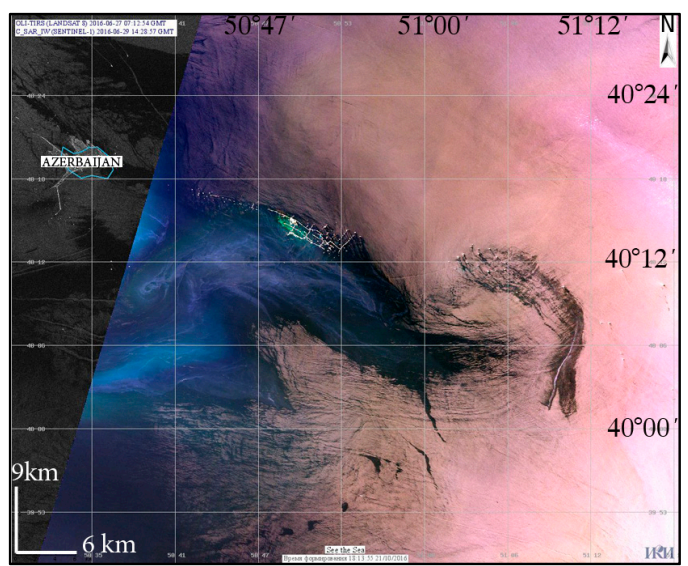

(b)

Figure 10. An example of joint analysis of optical and SAR data. (a) A part of a HH-polarized Sentinel-1 SAR image of 29 June 2016, 14:28 UTC, under low wind conditions; (b) a fusion of the Sentinel-1 SAR image and Landsat- 8 OLI -derived false-colour image obtained over the same area close in time. 


\section{Results}

\subsection{The Black Sea Surface Oil Pollution}

\subsubsection{The Black Sea Surface Oil Pollution Due to Ship Spillages}

Ship-related operational discharges of oil include:

- discharges of bilge water from machinery spaces;

- operational discharges of oil from machinery spaces;

- discharges of tank-washing residues and oily ballast water.

Figure 11a shows the cumulative map of oil-containing spills in the Black Sea revealed from SAR data for the years 2009-2011. Year-by-year numbers of oil spills detected are 219, 253, and 234 correspondingly, total polluted areas being 790, 806, and $768 \mathrm{sq} . \mathrm{km}$. All these pollution events are caused by spills of oil-containing waters from moving ships. As expected, the spills are concentrated along the main shipping routes such as Istanbul-Novorossiisk, Istanbul-Odessa and Istanbul-Tuapse. Besides, a large amount of spills is observed near the major ports of Bulgaria, Turkey, Romania and Ukraine (see Figure 1a).

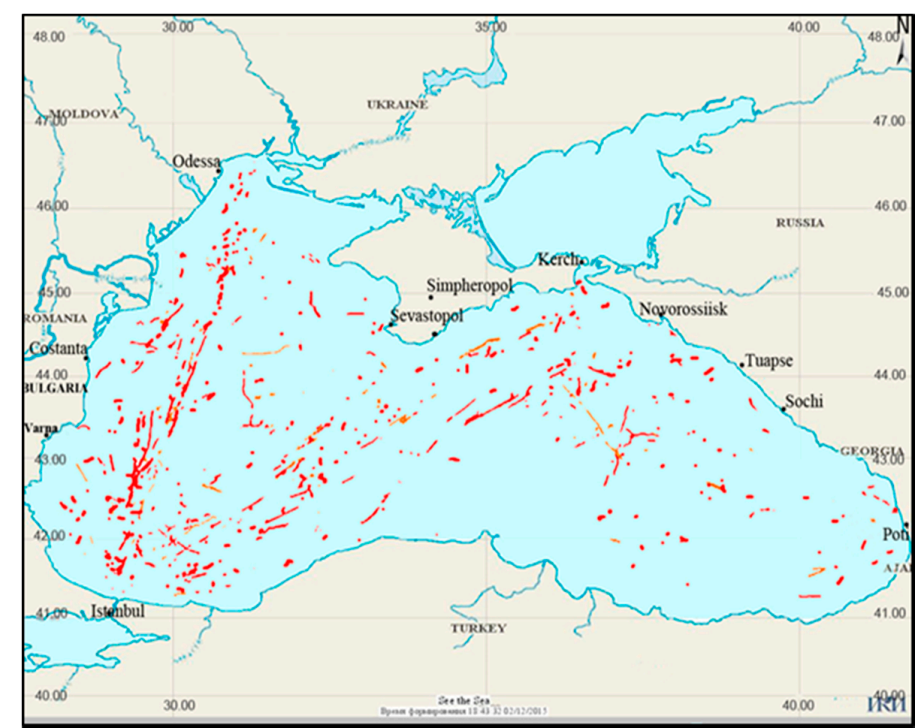

(a)

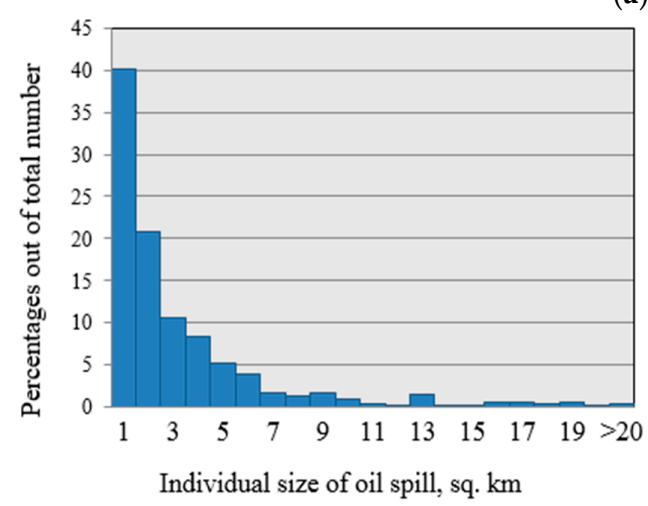

(b)

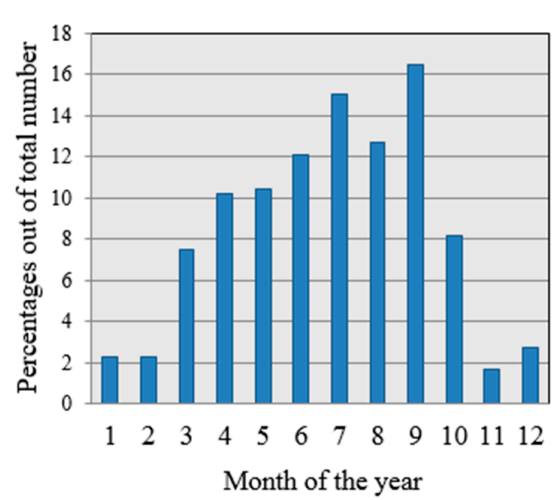

(c)

Figure 11. (a) Map of oil spills on the Black Sea surface revealed from satellite SAR imagery in 2009-2011; (b) individual spill size distribution; (c) monthly distribution of spills. 
Some numerical data on oil spills in the Black Sea revealed from satellite data are presented in Figure $11 \mathrm{~b}$,c. The area of individual detected oil spill varied from 0.1 to $40 \mathrm{sq}$. $\mathrm{km}$. It can be seen from the histograms that over $40 \%$ of spills did not exceed $1 \mathrm{sq} . \mathrm{km}$, and $80 \%$ were less than $5 \mathrm{sq} . \mathrm{km}$. Note that quite often ships discharge wastewaters several times along route over distances of dozens of kilometers.

Larger numbers of spills registered during warm season (March-October) could be explained by weather conditions more favorable for the recognition of spills in SAR images.

\subsubsection{Black Sea Surface Oil Pollution Due to Natural Hydrocarbon Showings}

Characteristic slick structures caused by natural hydrocarbon can be frequently observed in satellite data of the Black Sea south-eastern continental slope. The geographical distribution of these surface films is characterized by their persistent locations that correlate with geographical locations of natural hydrocarbon sources in this region.

Some examples of film pollution detected in SAR images taken over the continental slope in the south-eastern part of the Black Sea are shown in Figure 12. In most cases, surface film pollutions manifest themselves in this region as filamentary slicks, similar to biogenic films.

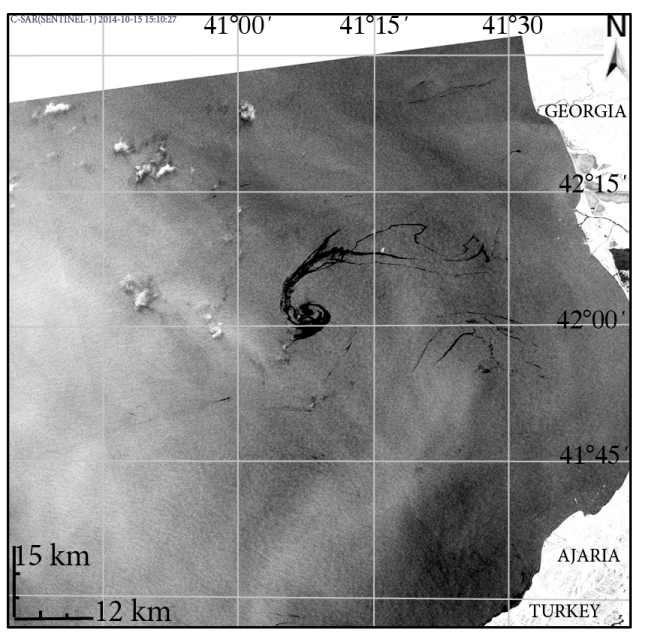

(a)

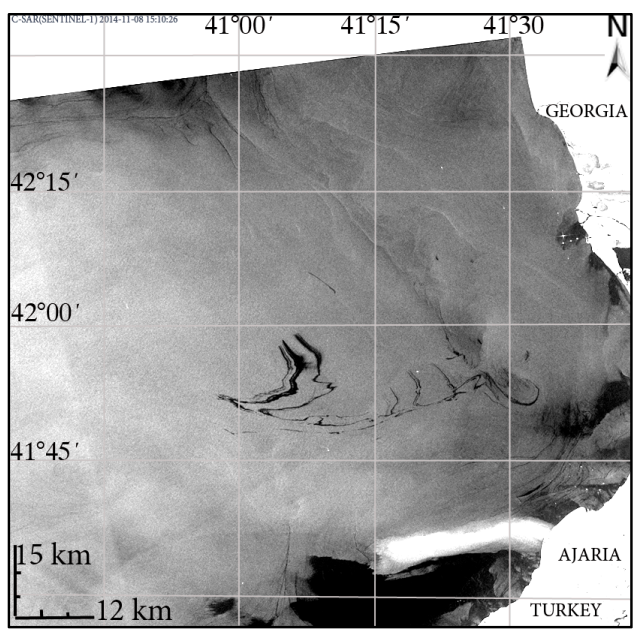

(b)

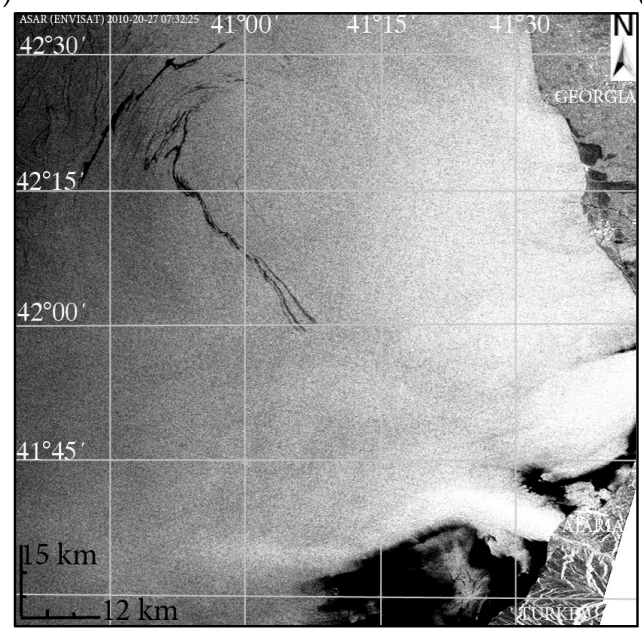

(c)

Figure 12. Surface slicks in the continental slope area offshore Georgia as seen in SAR imagery: (a) Sentinel-1 SAR, 15 October 2014, 15:10 UTC; (b) Sentinel-1 SAR, 8 November 2014, 15:10 UTC; (c) Envisat ASAR, 27 September 2011, 07:21 UTC. 
In the majority of radar images, these slicks appear as "coupled" structures. Comparison of slick locations detected in satellite imagery and methane seepage locations depicted in Figure 1b makes it possible to draw the conclusion that such coupled character is caused by natural hydrocarbons showings from the two closely-spaced methane seepages on the sea bottom: Colkheti Seep and Pechori Mound. These surface films can stretch along the flow lines of surface currents and reproduce the shape of local circulation pattern.

We analyzed all ERS-2 SAR and Envisat ASAR images of the Black Sea taken over the south-eastern continental slope in the period from January 2010 to December 2011 as well as Sentinel-1 SAR images taken from October 2014 to April 2015. A consolidated map of seepage slicks revealed in the SAR imagery in the study area is shown in Figure 13a. It was found that $49.5 \%$ of the radar images of the area for the period of 2010-2011 contained slick structures, whereas in the period of October 2014-April 2015 the slick structures were registered in 64\% of images (Figure 13b). The total surface area exposed to oil contamination in the vicinity of the seepages reaches approx. $800 \mathrm{sq} . \mathrm{km}$, which is a real danger to the ecology of the region. The slicks may drift distances up to $40 \mathrm{~km}$ driven by wind and local hydrodynamic processes. We can conclude from the analysis of the SAR data, that natural hydrocarbon showings occurred in the region more often in 2014-2015, but individual sizes of oil patches were bigger in 2010-2011 (Figure 13b,c).

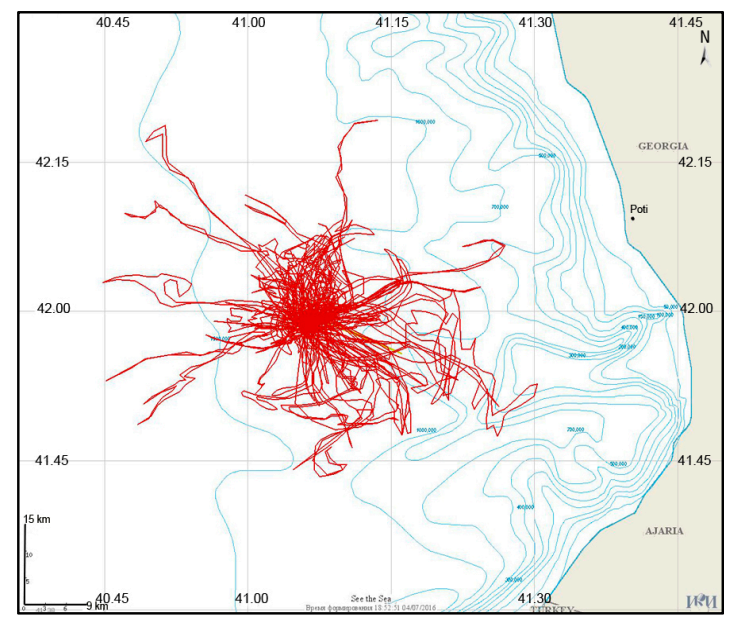

(a)

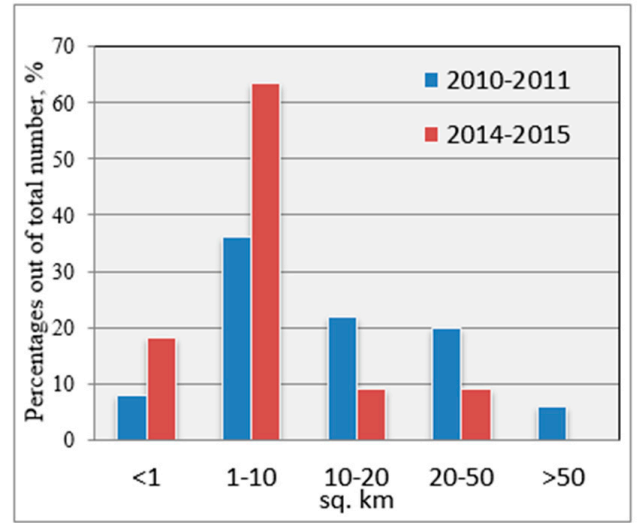

(b)

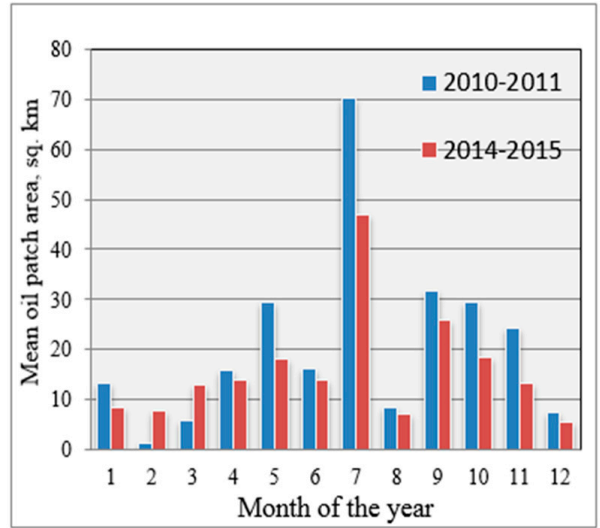

(c)

Figure 13. Analysis of SAR imagery of sea surface oil pollution due to seabed seepages in the south-eastern continental slope area: (a) consolidated map of oil patches; (b) size distributions of individual oil patches; (c) monthly means of oil patch sizes. 


\subsection{The Caspian Sea Surface Oil Pollution}

\subsubsection{Map of Oil Pollution in the Middle and Southwestern Caspian Sea}

Spatial distribution of oil films on the sea surface identified from the satellite data in the Middle and southern Caspian Sea is depicted in Figure 14. According to this map, two most heavily polluted regions can be identified. These are the region of Oil Rock oil-producing area (I); and the western edge of the South Caspian Depression (II).

Sea surface anthropogenic pollution caused by oil-containing discharges from ships can also be detected in SAR images of the Middle and Southern Caspian Sea. However, as opposed to what was observed in the Black Sea, illegal discharges in the Caspian Sea are not the major source of sea surface film pollution, although unfortunately their amount grows year-to-year. We estimate natural seabed hydrocarbon seepages to be the principal source of oil pollution in the Caspian Sea.

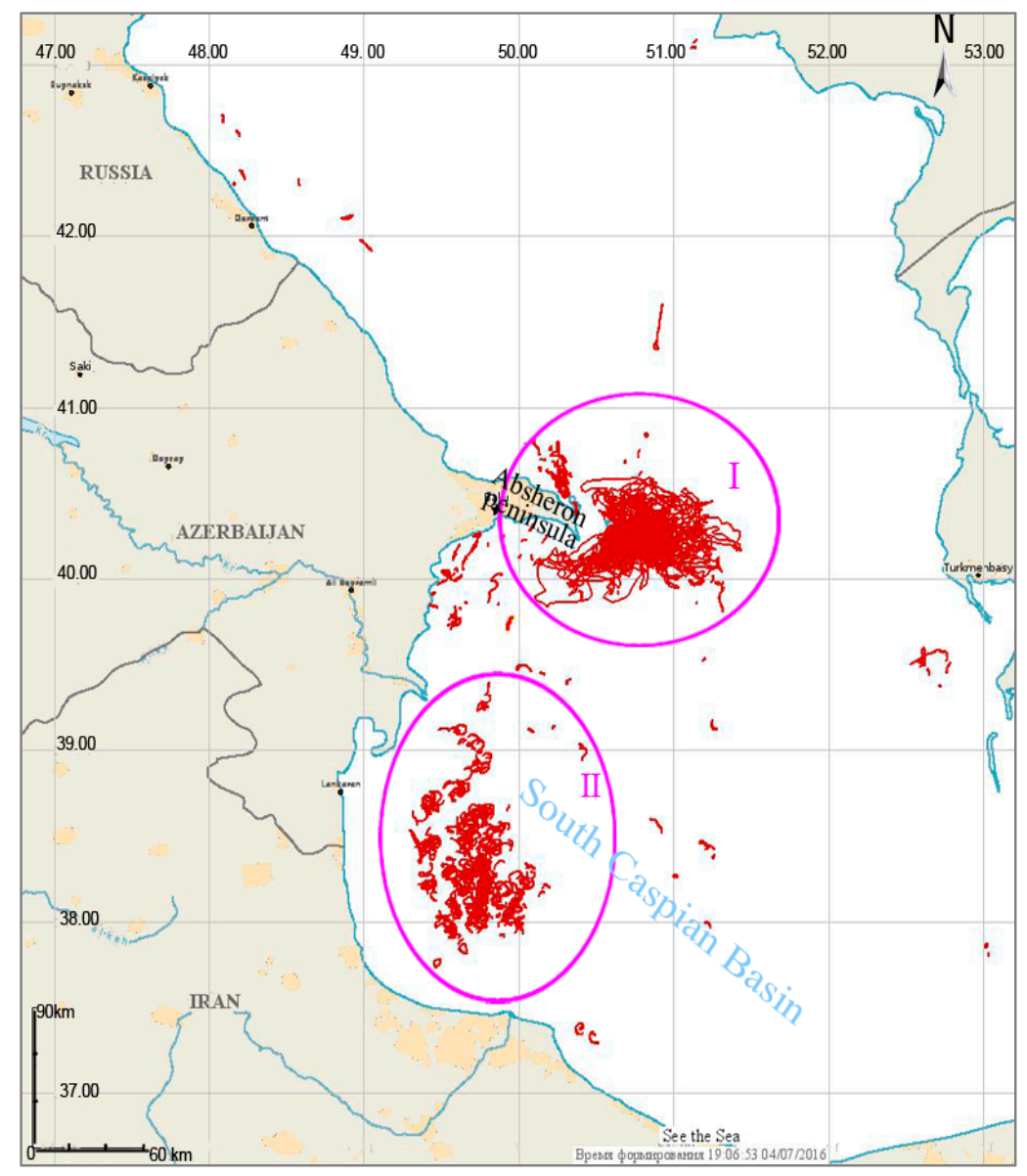

Figure 14. Map of oil slicks revealed from SAR imagery in the Middle and Southwestern Caspian Sea in 2010.

\subsubsection{Surface Pollution in the Oil Rocks Oil-Producing Area}

For this study we examined all ASAR Envisat images of the Caspian Sea obtained over Oil Rocks in the period from January 2010 to December 2011 as well as Sentinel-1 SAR images taken from October 2014 to June 2015. It was found that only $69.3 \%$ of SAR images of the test area contained signatures of oil patches near the oil platform. No slick structures were seen in the remaining images because of high/low wind conditions. In particular, in $22 \%$ of the images oil slicks were absent due to high winds, and in $8.7 \%$ due to low winds and, consequently, a large number of low backscatter areas not related to oil films. 
The distribution of individual sizes of oil patches near the oil-drilling platforms detected in SAR images is shown in Figure 15a. From the diagram, it follows that the characteristic areas of these patches are from 300 to $600 \mathrm{sq}$. km, but sometimes their areas may exceed $900 \mathrm{sq}$. km. It should be stressed that these estimates are only derived from SAR imagery and real areas measured in situ can considerably differ depending on local wind/wave conditions. Monthly means of oil patch sizes detected in SAR images were calculated as well. This distribution is shown in Figure 15b. It can be inferred from this diagram that oil patches sizes detected in the cold period, from October till April, are relatively small. This can be explained by intensification of atmospheric processes during this period and larger number of days with predominantly high wind speed, its average being $7.5 \mathrm{~m} / \mathrm{s}$. Storm winds are often observed in this period [47]. The calculated total surface area exposed to oil contamination in the Oil Rock oil-producing area reaches approx. 6260 sq. km, which is a danger to the ecology of the Caspian Sea.

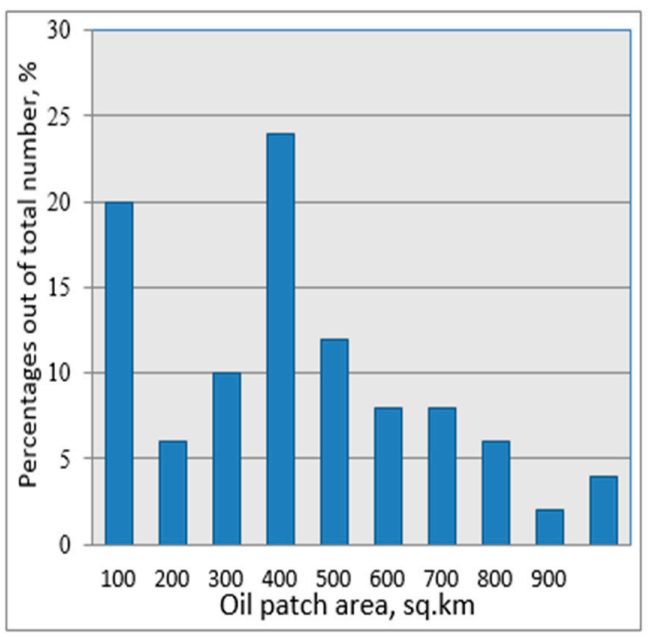

(a)

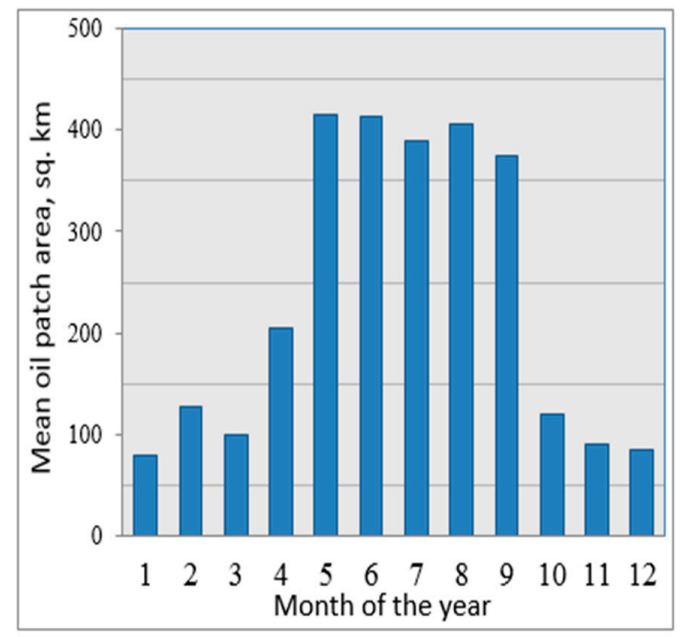

(b)

Figure 15. Oil Rocks SAR imagery statistics on oil patches for 2010: (a) distribution of individual sizes of oil patches; (b) monthly means of oil patch sizes.

We found that in this region, surface current often has a much more significant effect on oil propagation than local wind. Satellite data show that the evolution of an oil patch is a two-phase process. During the initial phase, the oil moves and spreads mostly under the influence of local winds. During the second phase, the oil can be entrained in a local current; travel with it long distances or be involved in a vortical motion. Trapped by current, oil can be transported in various directions, in general, not coinciding with wind direction, to considerable distances up to $70 \mathrm{~km}$. An example of such two-phase propagation is shown in Figure 16. At the time of data acquisition, the wind was southwesterly. Oil that appeared at the surface initially spread in the northeast direction under the wind (blue arrow outlines the first stage). At a distance of $6.5 \mathrm{~km}$ from the oil-extracting platform, the oil was trapped by a surface current shaped in an eddy dipole and began propagating northwest. Next, still carried by the dipole current, the oil changed propagation direction again to spread southwest from the initial point that is upwind, to a distance of $40 \mathrm{~km}$. This second stage is outlined by yellow arrows in the figure. 


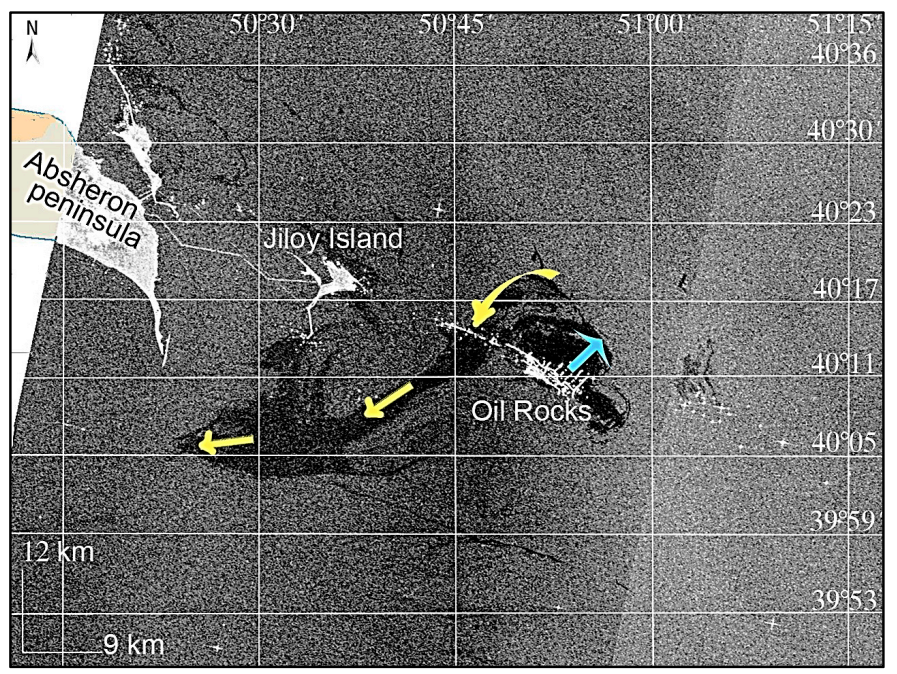

Figure 16. An example of oil patch evolution under the influence of local winds and currents. A part of an Envisat ASAR of 24 June 2010, 06:36 UTC. Total slick area is $325 \mathrm{sq}$. km. At the time of data acquisition, the maximal oil propagation distance was $44 \mathrm{~km}$ from the platform. See Figure 2 for enlarged regional context.

\subsubsection{Surface Pollution in the Southern Caspian Sea: Oil Slicks Due to Mud Volcanoes Activity}

We analyzed satellite images of the Caspian Sea near the South-Caspian depression. An analysis of spatial variability of surface manifestations of the type shown in Figure 17 revealed that their geographic distribution correlates with that of underwater mud volcanoes depicted in Figure 2c.

Some characteristic examples of satellite signatures of oil film surface pollution due to seabed mud volcano activities in the south-western part of the Caspian Sea are shown in Figure 17. It is clear that surface manifestations of oil slicks due to seabed mud volcanoes activity drastically differ from any other, either ship spills or natural hydrocarbon showings in the southeastern part of the Black Sea.

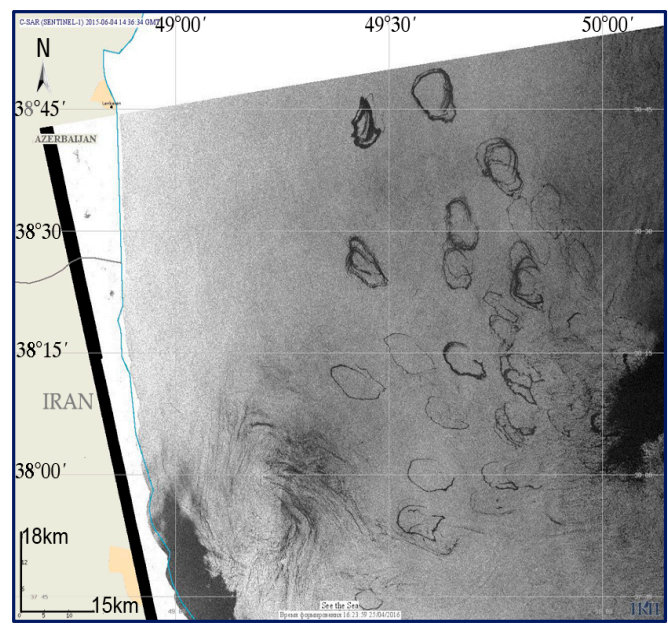

(a)

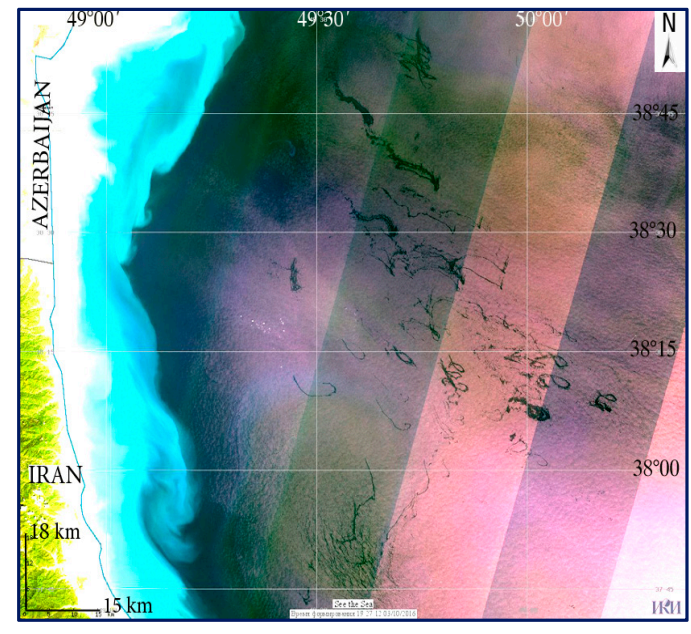

(b)

Figure 17. Mud volcanoes manifestations in satellite images via surfacing oil slicks: (a) A part of Sentinal-1 SAR image of 4 June 2015, 14:36 UTC; (b) A part of a colour composite Sentinel-2 MSI image of 19 August 2016, 07:26 UTC.

The correlation between seepages manifestations in SAR images and earthquakes in the South Caspian and neighboring areas was studied. A strong correlation was discovered between seepage 
manifestations in the satellite images and earthquakes of magnitudes 3-4 on the Richter scale. Scientific publications on the subject provide substantial evidence that eruptions of mud volcanoes are caused by earthquakes. Since epicenters of the earthquakes are typically located at a distance from volcanoes, seismic waves take some time to reach the volcanoes. This entails volcanoes awakening not immediately at the day of the earthquake but several days or even weeks after the earthquake, depending on the distance from the epicenter, the earthquake magnitude and the depth of the earthquake [56-58].

\section{Discussion}

Public interest in the problem of oil pollution mainly arises during dramatic tanker catastrophes. Nevertheless, oil and petroleum products spills at sea take place all the time, and it would be a delusion to consider tanker accidents the main environmental danger. Oil spills cause contamination of seawater, shores, and beaches, which may persist for several months and represent a threat to marine resources.

Today one can speak about largely fragmented information available on the parameters of surface oil pollution of the Black and Caspian Seas. Therefore, mapping of the pollution, identification of its sources and spreading forecast are currently of extreme importance.

Our results include a map of oil spills created on the basis of satellite data for the whole aquatic area of the Black Sea. Previously, such maps were compiled only for the north-eastern part of the Black Sea [29]. We outlined areas of the heaviest surface pollution due to ship discharges. As expected, the spillages are concentrated along the main shipping routes such as Istanbul-Novorossiisk, Istanbul_Odessa and Istanbul-Tuapse. Besides, a lot of spills are observed near the major ports of Bulgaria, Turkey, Romania and Ukraine. Larger numbers of spills registered during warm season (March-October) could be explained by weather conditions more favorable for the recognition of spills in SAR images. Most spills do not exceed 5 sq. $\mathrm{km}$ in size. However, sometimes ships discharge oil-containing wastewaters several times along route over distances of dozens of kilometers. Under the influence of wind and waves, the film spreads broadly over the sea surface. In this case, oil patches covering areas of tens of square kilometers can be detected. Our long-term observation shows that illegal ship discharges have become very common in the Black Sea and, in aggregate, they can cause more harm to the sea ecosystems than individual oil spills resulting from tanker crash. As opposed to what is observed in the Black Sea, illegal discharges are not the main source of sea surface film pollution in the Caspian Sea, although their amount keeps growing every year.

An important problem addressed in our study is the detection of oil pollution caused by natural hydrocarbon seepages from the sea bottom using satellite data. The probability is high for natural hydrocarbon manifestations in SAR imagery to be interpreted as ship discharges or biogenic films. Therefore, we recommend comparing satellite images with a map of possible sources of regular pollution (deepwater discharge of waste waters, oil terminals, river estuaries, underwater mud volcanoes, etc.) to reduce the probability of "false positives" during routine monitoring.

A comparison of surface manifestations of seabed oil seepages in the Black and the Caspian Seas has demonstrated significant differences. They can be explained by the differences in origins and compositions of the hydrocarbons that reach the surface as well as by different hydrodynamic conditions in these regions. In the Black Sea, surface manifestations of oil slicks from hydrocarbon seepages are not affected by seismic activity, in contrast to the Caspian Sea, where a correlation between the occurrence of slick manifestations in satellite images and earthquakes of magnitudes 3-4 on the Richter scale was established. In [26], a comparison of oil pollution in the Black and Caspian Seas is made, but only with regard to ship spills. No comparisons of sea surface oil pollution due to seabed natural hydrocarbon seepages in the Black and Caspian Seas have been reported so far.

Our observations show that the main source of the open sea surface pollution in the area of Absheron and Baku archipelagoes in the Caspian Sea is the ingress of the oil caused by oil production and oil-well drilling, by oil outflow during pipeline breaks as well as by oil outflow from natural seepages at the sea bottom. We have found that in the Oil Rock area, surface currents have sometimes a 
much more significant effect on oil propagation than local winds. The system of surface currents in the Oil Rocks area is rather complicated and unstable featuring highest current velocities in the Caspian Sea. Regardless of wind direction, oil can be transported great distances by the currents. Usually, this effect is neglected in pollution propagation forecasts. It should be stressed that the tasks of satellite monitoring of sea surface pollution and sea state are closely related because pollutants become part of a marine environment and evolve according to its intrinsic mechanisms.

Our study is based not only on SAR imagery, as the majority of known studies of sea surface oil pollution, but also on a combined use of different in nature (microwave radar, visual and infrared) quasi-concurrent satellite information. Satellite SAR and multispectral optical instruments have advantages and limitations in detecting oil and petroleum products spills on the sea surface. The advantages of SAR are: absolute sensitivity to sea surface roughness in centimeter wave range that is largely damped by oil films; independence of cloud coverage and solar illumination; high spatial resolution in wide imaging swath. The SAR limitations are: near-surface wind of $2-10 \mathrm{~m} / \mathrm{s}$, possible ambiguous interpretation because of oil look-alikes. A considerable effort was devoted to revealing the dependence of radar signatures of oil patches on the sea surface wind/wave conditions. We discovered that sizes of oil slicks retrieved from SAR imagery strongly depend on wind/wave conditions and may differ from real sizes measured in situ. Sizes of polluted areas derived from SAR data taken at high wind speed and/or in presence of active atmospheric processes are typically underestimated, while sizes of polluted areas derived from radar data taken at low winds overestimated. One should take this into consideration when estimating sea surface oil pollution dimensions based SAR data only [28]. The advantages of multispectral optical sensors are high spatial resolution in wide viewing swath and, in certain conditions, the capability to assess surface film thickness. The limitations of optical sensors are: low solar illumination and substantial cloud cover. Combining for analysis various types of remotely sensed data acquired at different electromagnetic wavelengths can significantly improve the effectiveness of sea surface oil pollution detection.

It should be noted that due to fast increase of the remote sensing data flow, an effective data management becomes possible only with the use of specially developed systems and technologies allowing handling vast and continuously enlarging data archives. At present, we use a distributed satellite information STS system to process and analyze satellite and auxiliary data, create and develop information products and techniques for the detection, tracking, characterization, and monitoring the effects of oil pollution of the sea surface. STS provides storage facilities, tools for joint processing and analysis of data different in physical nature (active and passive microwave sensing, data in visual and infrared bands), dimension, spatial and spectral resolution, and acquisition time.

Our study and the results obtained bring new knowledge both on the spatial and temporal variability of surface oil pollution in the Black and Caspian Seas and the capabilities of their reliable detection using satellite data.

\section{Conclusions}

We demonstrated a clear demand for regular operational satellite monitoring of surface pollution in inner seas in order to reveal the source, assess the scale and predict spreading and evolution of pollution.

We showed that combined analysis of various satellite data obtained in different ranges and at different spatial resolutions contributes to a more comprehensive interpretation of the data and helps a better understanding of surface oil pollution properties. About 4500 high resolution SAR images of the Black and Caspian Seas acquired in the period from February 2009 to April 2012 by Envisat ASAR and ERS-2 SAR were processed and analyzed. Sentinel-1A SAR data were also analyzed revealing the capabilities of this new mission to continue oil spill monitoring initiated by the ESA's ERS/Envisat missions. Most of the SAR images were complemented with visual and infrared data for the times close to SAR data acquisitions. The large amount of the data analyzed allowed us to make some generalizations and obtain statistically significant results on spatial and temporal variability of 
various sea surface film manifestations in satellite images. We can conclude that satellite data handling instrumentation developed in the framework of the STS information system allowed us to carry out detailed data analysis with the multiple satellite data sources. This service includes instruments for complex analysis of various processes and phenomena in world's oceans, qualitative and quantitative estimates of their properties, identifying their spatial and temporal variations, revealing conditions of their generation and evolution. The use of STS helps advance technologies for the detection, tracking, characterization, and monitoring the effects of oil spills.

We investigated two main types of surface oil pollution of the Black and Caspian Seas: oil-containing ship spills and natural seabed seepages of oil. For each type of pollution and each sea, regions of regular pollution occurrence were determined, polluted areas were estimated, and specific manifestation features were revealed.

A consolidated map of oil-containing spills in the whole aquatic area of the Black Sea derived from 2009 to 2011 satellite data is created. Areas of the heaviest surface pollution due to discharges of oil and petroleum products from ships were identified. All these areas are indeed zones of ecological risk. Year-to-year numbers of oil spills detected are 219, 253, and 234, correspondingly, the total polluted areas being 790, 806, and $768 \mathrm{sq}$. km. The area of individual detected oil spill varied from 0.1 to $40 \mathrm{sq}$. $\mathrm{km}$. Average monthly numbers of detected spills and distribution of individual sizes of oil-containing spills are calculated. No similar estimates involving the whole area of the Black Sea have been reported before.

In the Black Sea, we detected manifestations of seabed hydrocarbon seepages, primarily in the eastern part of the sea. A consolidated map of seepage slicks revealed in satellite data was generated. It was found that the slicks can drift distances up to $40 \mathrm{~km}$ driven by wind and local hydrodynamic processes. The total surface area exposed to oil contamination the vicinity of the seepages reaches approx. $800 \mathrm{sq}$. km.

We revealed that in the Caspian Sea, there is considerably less pollution caused by illegal oil spills due to smaller ship traffic. We found out that the main source of oil pollution there is natural seabed hydrocarbon seepages. Two regions of the heaviest surface pollution of the Caspian Sea are identified based on satellite data: the area of the Absheron and Baku Archipelagoes and the western edge of the South-Caspian Depression. It is discovered that oil patches with areas from 300 to $600 \mathrm{sq}$. $\mathrm{km}$ are quite common for the region of Absheron and Baku near the Oil Rocks oil-producing site, and sometimes their areas exceed $900 \mathrm{sq}$. km. A map of oil pollution in this region revealed by satellite imagery was created. The total area affected by oil pollution around the Oil Rocks platform was estimated at approx. $6260 \mathrm{sq}$. km, which is a great threat to the ecology of the Caspian Sea.

The examples and numerical data we provide on sea surface oil pollution from both discharges from ships and seepages from the sea floor reflect the influence of the pollution on the sea environment.

Acknowledgments: This research is supported by the Russian Science Foundation under the project \# 14-17-00555. Satellite radar data were provided by the European Space Agency in the framework of the C1P.6342, Bear 2775 and C1P.1027 projects. Basic functionality of the STS portal is implemented in frame of Theme "Monitoring", state register No. 01.20.0.2.00164 (FASO Russia). The authors are grateful to Tatiana Yu. Bocharova (Space Research Institute, Moscow, Russia) for the assistance in satellite data processing. We would like to thank all anonymous reviewers and Academic Editors for their valuable comments and suggestions.

Author Contributions: Both authors contributed equally to the paper. Olga Lavrova and Marina Mityagina analyzed data, contributed with ideas, discussions, and writing. Marina Mityagina designed the architecture of the manuscript and prepared the figures.

Conflicts of Interest: The authors declare no conflict of interest.

\section{References}

1. Horning, N.; Robinson, J.; Sterling, E.; Turner, W.; Spector, S. Remote Sensing for Ecology and Conservation: A Handbook of Techniques; Oxford University Press: Oxford, UK, 2010.

2. Malthus, T.J.; Mumby, P.J. Remote sensing of the coastal zone: An overview and priorities for future research. Int. J. Remote Sens. 2003, 24, 2805-2815. [CrossRef] 
3. Gade, M.; Alpers, W. Using ERS-2 SAR images for routine observation of marine pollution in European coastal waters. Sci. Total Environ. 1999, 237, 441-448. [CrossRef]

4. Kostianoy, A.; Lavrova, O. Oil pollution in the Baltic Sea; Springer: Berlin/Heidelberg, Germany, 2014.

5. Cheng, Y.; Li, X.; Xu, Q.; Garcia-Pineda, O.; Andersen, O.; Pichel, W. SAR observation and model tracking of an oil spill event in coastal waters. Mar. Pollut. Bull. 2011, 62, 350-363. [CrossRef] [PubMed]

6. Nunziata, F.; Migliaccio, M.; Li, X. Sea oil slick observation using hybrid-polarity SAR architecture. IEEE J. Ocean. Eng. 2014, 40, 426-440. [CrossRef]

7. Klemas, V. Tracking oil slicks and predicting their trajectories using remote sensors and models: Case studies of the Sea Princess and Deepwater Horizon oil spills. J. Coast. Res. 2010, 26, 789-797. [CrossRef]

8. Lavrova, O.Y.; Kostianoy, A.G.; Lebedev, S.A.; Mityagina, M.I.; Ginzburg, A.I.; Sheremet, N.A. Complex Satellite Monitoring of the Russian Seas; IKI RAN: Moscow, Russia, 2011. (In Russian)

9. Mityagina, M.I.; Lavrova, O.Y.; Bochorova, T.Y. Satellite monitoring of oil pollution of the sea surface. Sovrem. Probl. Distantsionnogo Zondirovaniya Zemli Kosm. 2015, 12, 130-149. (In Russian)

10. Grishin, N.; Kostianoy, A. Satellite monitoring of suspended matter pollution resulted from the Nord Stream gas pipeline construction in Russian waters of the Baltic Sea in 2010-2011. Int. Water Technol. J. 2012, 2, 80-89.

11. Pilon, R.O.; Purves, C.G. Radar imagery of oil slicks. IEEE Trans. Aerosp. Electron. Syst. 1973, AES-9, $630-636$. [CrossRef]

12. Kudryavtsev, V.N.; Chapron, B.; Myasoedov, A.G.; Collard, F.; Johannessen, J.A. On Dual Co-Polarized SAR measurements of the ocean surface. IEEE Geosci. Remote Sens. Lett. 2013, 10, 761-765. [CrossRef]

13. Mityagina, M.I.; Churyumov, A.N. Mechanisms of radar signal formation in the sea surface oil pollution area. Sovrem. Probl. Distantsionnogo Zondirovaniya Zemli Kosm. 2006, 3, 135-139. (In Russian)

14. Skrunes, S.; Brekke, C.; Eltoft, T. Oil spill characterization with multi-polarization C- and X-band SAR. In Proceedings of the 2012 IEEE International Geoscience and Remote Sensing Symposium, Munich, Germany, 22-27 July 2012.

15. Ermakov, S. Slicks in SAR imagery of the sea surface. In Proceedings of the SPIE 8536, SAR Image Analysis, Modeling, and Techniques XII, Edinburgh, UK, 21 November 2012.

16. Brekke, C.; Holt, B.; Jones, C.; Skrunes, S. Discrimination of oil spills from newly formed sea ice by Synthetic Aperture Radar. Remote Sens. Environ. 2014, 145, 1-14. [CrossRef]

17. Lu, J. Marine oil spill detection, statistics and mapping with ERS SAR imagery in South-East Asia. Int. J. Remote Sens. 2003, 24, 3013-3032. [CrossRef]

18. Karathanassi, V.; Topouzelis, K.; Pavlakis, P.; Rokos, D. An object-oriented methodology to detect oil spills. Int. J. Remote Sens. 2006, 27, 5235-5251. [CrossRef]

19. Ferraro, G.; Meyer-Roux, S.; Muellenhoff, O.; Pavliha, M.; Svetak, J.; Tarchi, D.; Topouzelis, K. Long term monitoring of oil spills in European seas. Int. J. Remote Sens. 2009, 30, 627-645. [CrossRef]

20. Shcherbak, S.S.; Lavrova, O.Y.; Mityagina, M.I.; Bocharova, T.Y.; Krovotyntsev, V.A.; Ostrovskii, A.G. Multisensor satellite monitoring of seawater state and oil pollution in the northeastern coastal zone of the Black Sea. Int. J. Remote Sens. 2008, 29, 6331-6345. [CrossRef]

21. Lavrova, O.; Bocharova, T.; Mityagina, M. Satellite monitoring of the oil spill in the Kerch Strait. In Oil Spill Accident in the Kerch Strait in November 2007; Korshenko, A.A., Ilyin, Y., Velikova, V., Eds.; Black Sea Commission Publications, Nauka: Moscow, Russia, 2011; pp. 161-166.

22. Kim, T.S.; Park, K.A.; Li, X.; Lee, M.; Hong, S.; Lyu, S.J.; Nam, S. Detection of the Hebei Spirit oil spill on SAR Imagery and its temporal evolution in a coastal region of the Yellow Sea. Adv. Space Res. 2015, 56, 1079-1093. [CrossRef]

23. Kostianoy, A.G.; Lavrova, O.Y.; Solovyov, D.M. Oil pollution in coastal waters of Nigeria. In Remote Sensing of the African Seas; Barale, V., Gade, M., Eds.; Springer: Heidelberg, Germany, 2014; pp. 149-166.

24. Lavrova, O.Y.; Kostianoy, A.G. Catastrophic oil spill in the Gulf of Mexico in April-May 2010. Izv. Atmos. Ocean. Phys. 2011, 47, 1114-1118. [CrossRef]

25. European Maritime Safety Agency. Available online: http://www.emsa.europa.eu/csn-menu/csn-how-itworks.html (accessed on 2 May 2016).

26. Ivanov, A.Y.; Kucheiko, A.A. Distribution of oil spills in inland seas based on SAR image analysis: A comparison between the Black Sea and the Caspian Sea. Int. J. Remote Sens. 2016, 37, 2101-2114. [CrossRef]

27. Boev, A.G.; Bychkov, D.M.; Matveyev, A.Y.; Tsymbal, V.N. Radar satellite multi-angle diagnostics of sea surface oil pollution. Sovrem. Probl. Distantsionnogo Zondirovaniya Zemli Kosm. 2013, 10, 166-172. (In Russian) 
28. Ivanov, A.Y.; Dostovalov, M.Y.; Sineva, A.A. Characterization of oil pollution around the oil rocks production site in the Caspian Sea using spaceborne polarimetric SAR imagery. Izv. Atmos. Ocean. Phys. 2012, 48, 1014-1026. [CrossRef]

29. Bedritskii, A.I.; Asmus, V.V.; Krovotyntsev, V.A.; Lavrova, O.Y.; Ostrovskii, A.G. Satellite monitoring of pollution in the Russian sector of the Azov and Black Seas in 2003-2007. Russ. Meteorol. Hydrol. 2007, 32, 669-674. [CrossRef]

30. Jenkins, A.D.; Jacobs, S.J. Wave damping by a thin layer of viscous fluid. Phys. Fluids 1997, 9, 1256-1264. [CrossRef]

31. Alpers, W.; Huhnerfuss, H. The damping of ocean waves by surface films: A new look at an old problem. J. Geophys. Res. 1989, 94, 6251-6265. [CrossRef]

32. Espedal, H.; Wahl, T. Satellite SAR oil spill detection using wind history information. Int. J. Remote Sens. 1999, 20, 49-65. [CrossRef]

33. Brekke, C.; Solberg, A. Oil spill detection by satellite remote sensing. Remote Sens. Environ. 2005, 95, 1-13. [CrossRef]

34. Migliaccio, M.; Nunziataa, F.; Buonoa, A. SAR polarimetry for sea oil slick observation. Int. J. Remote Sens. 2015, 36, 3243-3273. [CrossRef]

35. Gade, M.; Alpers, W.; Hühnerfuss, H.; Masuko, H.; Kobayashi, T. The imaging of biogenic and anthropogenic surface films by a multi-frequency multi-polarization synthetic aperture radar measured during the SIR-C/X-SAR Missions. J. Geophys. Res. 1998, 103, 18851-18866. [CrossRef]

36. Kostianoy, A.G.; Lavrova, O.Y.; Mityagina, M.I.; Solovyov, D.M.; Lebedev, S.A. Satellite monitoring of oil pollution in the Southeastern Baltic Sea. In Oil Pollution in the Baltic Sea; Kostianoy, A.G., Lavrova, O.Y., Eds.; Springer: Berlin/Heidelberg, Germany; New York, NY, USA, 2013; Volume 27, pp. 125-154.

37. Lavrova, O.Y.; Mityagina, M.I. Satellite monitoring of oil slicks on the Black Sea surface. Izv. Atmos. Ocean. Phys. 2013, 49, 897-912. [CrossRef]

38. Mityagina, M.I.; Lavrova, O.Y. Satellite survey in the Black Sea coastal zone. Int. Water Technol. J. 2012, 2, 67-79.

39. Mityagina, M.I.; Lavrova, O.Y. Multi-sensor satellite survey of surface oil pollution in the Caspian Sea. In Proceedings of the SPIE 9638, Remote Sensing of the Ocean, Sea Ice, Coastal Waters, and Large Water Regions, Toulouse, France, 21 September 2015.

40. Marine Vessel Traffic. Available online: http://www.marinevesseltraffic.com/2013/04/marine-traffic.html (accessed on 29 May 2016).

41. Körber, J.H.; Sahling, H.; Pape, T.; Ferreira, K.S.; McDonald, I.; Bohrmann, G. Natural oil seepage at Kobuleti Ridge, eastern Black Sea. Mar. Petrol. Geol. 2014, 50, 68-82. [CrossRef]

42. Reitz, A.; Pape, T.; Haeckel, M. Sources of fluids and gases expelled at cold seeps offshore Georgia, eastern Black Sea. Geochim. Cosmochim. Acta 2011, 75, 3250-3268. [CrossRef]

43. Klaucke, I.; Sahling, H.; Börk, D.; Weinrebe, W.; Bohrmann, G. Mapping deep-water gas emissions with sidescan sonar. EOS Trans. Am. Geophys. Union. 2005, 86, 341-346. [CrossRef]

44. Aliyev, N. Oil and Oil Factor on the Economics of Azerbaijan in the XXI-th Century; Letterpress: Baku, Azerbaijan, 2010.

45. Aliyev, I. Caspian Oil of Azerbaijan; Izvestiya: Moscow, Russia, 2003.

46. Brandon, S. Oil on troubled waters. Focus Cent. Asia 1995, 22, 12-16.

47. Mammadov, R.M. Caspian Sea: Hydrometeorological Variability and Ecogeographical Problems; ELM: Baku, Azerbaijan, 2007.

48. European Environment Agency. Available online: http://www.eea.europa.eu/data-and-maps/figures/ selected-oil-and-gas-installations-and-projects-in-the-caspian-sea (accessed on 29 May 2016).

49. Aliyev, A.A.; Rahmanov, R.R. Qualitative assessment of mud volcano activity in Azerbaijan. Izv. NANA Earth Sci. 2008, 2, 47.

50. MacDonald, I.R.; Guinasso, N.L., Jr.; Acleson, S.G.; Amos, J.F.; Duckworth, R.; Sassen, R.; Brooks, J.M. Natural oil slicks in the Gulf of Mexico visible from Space. J. Geophys. Res. 1993, 98, 16351-16364. [CrossRef]

51. Evtushenko, N.V.; Ivanov, A.Y. Oil seeps in the southeastern Black Sea studied using satellite synthetic aperture radar images. Izv. Atmos. Ocean. Phys. 2013, 49, 913-918. [CrossRef]

52. Sentinels Scientific Data Hub. Available online: https://scihub.copernicus.eu/dhus/\#/home (accessed on 29 May 2016). 
53. Mityagina, M.I.; Lavrova, O.Y.; Uvarov, I.A. See the Sea: Multi-user information system for investigating processes and phenomena in coastal zones via satellite remotely sensed data, particularly hyperspectral data. In Proceedings of the SPIE 9240, Remote Sensing of the Ocean, Sea Ice, Coastal Waters, and Large Water Regions 2014, Amsterdam, The Netherlands, 22 September 2014.

54. Loupian, E.A.; Matveev, A.A.; Uvarov, I.A.; Bocharova, T.Y.; Lavrova, O.Y.; Mityagina, M.I. The satellite service See the Sea-A tool for the study of oceanic phenomena and processes. Sovrem. Probl. Distantsionnogo Zondirovaniya Zemli Kosm. 2012, 9, 251-261. (In Russian)

55. Jackson, C.R.; Alpers, W. The role of the critical angle in brightness reversals on sunglint images of the sea surface. J. Geophys. Res. 2010, 115. [CrossRef]

56. Mellors, R.; Kilb, D.; Aliyev, A.A.; Gasanov, A.; Yetirmishli, G. Correlations between earthquakes and large mud volcano eruptions. J. Geophys. Res. 2007, 112. [CrossRef]

57. Aliyev, A.A. Geology, Geophysics, Oil and Gas Content; Nafta: Baku, Azerbaijan, 2004.

58. Aliyev, A.A.; Quliyev, I.S.; Rahmanov, R.R. Catalogue of Mud Volcanoes Eruptions of Azerbaijan (1810-2007); Nafta-Press: Baku, Azerbaijan, 2009.

(C) 2016 by the authors; licensee MDPI, Basel, Switzerland. This article is an open access article distributed under the terms and conditions of the Creative Commons Attribution (CC-BY) license (http://creativecommons.org/licenses/by/4.0/). 